\title{
Food for fuel: The effect of the US biofuel mandate on poverty in India
}

\author{
UjJayant Chakravorty \\ Department of Economics, Tufts University \\ Marie-HéLène Hubert \\ University of Rennes, CNRS \\ Beyza Ural Marchand \\ Department of Economics, University of Alberta
}

\begin{abstract}
More than $40 \%$ of US grain is used for energy due to the Renewable Fuel Mandate (RFS). There are no studies of the global distributional consequences of this purely domestic policy. Using micro-level survey data, we trace the effect of the RFS on world food prices and their impact on household level consumption and wage incomes in India. We first develop a partial equilibrium model to estimate the effect of the RFS on the price of selected food commodities-rice, wheat, corn, sugar, and meat and dairy, which together provide almost $70 \%$ of Indian food calories. Our model predicts that world prices for these commodities rise by $8-16 \%$ due to the RFS. We estimate the price pass-through to domestic Indian prices and the effect of the price shock on household welfare through consumption and wage incomes. Poor rural households suffer significant welfare losses due to higher prices of consumption goods, which are regressive. However, they benefit from a rise in wage incomes, mainly because most of them are employed in agriculture. Urban households also bear the higher cost of food, but do not see a concomitant rise in wages because only a small fraction of them work in food-related industries. Welfare losses are greater among urban households. However, more poor people in India live in villages, so rural poverty impacts are larger in magnitude. We estimate that the mandate leads to about 25 million new poor: 21 million in rural and 4 million in the urban population.
\end{abstract}

Keywords. Biofuels, distributional effects, household welfare, renewable fuel standard, poverty.

Ujjayant Chakravorty: uj jayant . chakravorty@tufts .edu

Marie-Hélène Hubert: marie-helene . hubert@univ-rennes1.fr

Beyza Ural Marchand: beyza. ural@ualberta. ca

We would like to thank the Social Sciences and Humanities Research Council (Insight Development Grant 430-2011-0635) and the French National Research Agency (Grant ANR-14-CE05-0008) for generous research support, seminar participants at Berkeley, CESifo Munich, EPA, ETH Zurich, Maryland, Ohio State, Paris School of Economics, Resources for the Future, Toulouse School of Economics, Tufts, Vanderbilt, Virginia Tech, and Wellesley College; and conference participants at the ASSA Annual Meetings, Canadian Economic Association Meetings, European Resource and Environmental Economics Meetings, Statistics Norway and the Indian Growth and Development Economics Conference at ISI Delhi. We would like to thank Kyle Emerick for helpful comments and Alausa Waleem for excellent research assistance.

(C) 2019 The Authors. Licensed under the Creative Commons Attribution-NonCommercial License 4.0. Available at http://qeconomics.org. https://doi.org/10.3982/QE942 
JEL CLASSIFICATION. D31, O12, Q24, Q42.

\section{INTRODUCTION}

The United States has been the most aggressive nation in encouraging the use of biofuels in the transportation sector. About $10 \%$ of US gasoline now comes from ethanol produced from corn, making it the largest consumer of biofuels in the world. This share is expected to rise several-fold with the advent of second generation biofuels under the Renewable Fuel Standard (RFS) (EPA (2010)). ${ }^{1}$ This policy is controversial because it uses scarce land resources that displace food for energy production, leading to an increase in food prices (Rosenthal (2011)). Several studies have attributed past food price shocks in US and world markets to the sharp increase in biofuel production, especially from corn ethanol. ${ }^{2}$

The RFS induces an increase in the price of food commodities and is well established. ${ }^{3}$ However, given that the US is a major agricultural nation as well as the largest consumer of transport fuels, the distributional effects of this price increase may be significant, and have not been rigorously studied. Little is known about the overall poverty impacts of the mandate on other nations. The effects may be negative through the higher cost of consumption, or positive, if wages and income in the agricultural sector of other nations increase. This is the focus of the present paper. Using micro-level survey data, we estimate the effect of the RFS through consumption and wage impacts among households in India. India is an important country to study because of its high incidence of poverty. According to the multidimensional poverty index, which accounts for health, education, and living standards, eight Indian states together have more poor people than the 26 poorest African states combined (UNDP (2010)). About a fifth of the population suffers from malnutrition (FAO (2010)).

We proceed in two steps: first, we calibrate a partial equilibrium model to trace the effect of the RFS on the world market for specific crops which consume a significant acreage and are important to the Indian diet, while aggregating the ones less important. ${ }^{4}$ This calibrated model captures critical dynamic effects such as allowing for new land to be converted to farming when crop prices rise. The goal is to predict price changes that are inclusive of adjustment processes in the world economy. We explicitly model shocks in parameters such as crop yields and food and fuel price elasticities through Monte Carlo simulations that generate stochastic distributions of price effects with corresponding standard errors. Based on mean impacts, this model predicts that the RFS raises long-run food commodity prices in the world market by about $8-16 \%$. These estimates suggest a significant price increase, but modest relative to previous studies.

\footnotetext{
${ }^{1}$ Brazil, the European Union, China, and other countries have similar policies that divert corn, sugar cane, and other crops from food to energy.

${ }^{2}$ See, for example, Mitchell (2008), Rosegrant, Zhu, Msangi, and Sulser (2008), and Hausman, Auffhammer, and Berck (2012). They report significant price increases for different food commodities of the order of $20-70 \%$.

${ }^{3}$ Although there may be differences in the estimated magnitude of price effects, especially in the short and long run.

${ }^{4}$ We study rice, wheat, corn, sugar, and meat and dairy, which together supply about $70 \%$ of the calories for the average Indian household.
} 
Next, we use detailed microlevel household data to examine how these predicted commodity price shocks affect welfare among households in India through the cost of consumption and wage incomes. We allow for household heterogeneity in terms of their expenditure shares, factor endowments, income, geographical location, and household structure, and identify the groups that are most impacted. In order to incorporate the limited pass-through of world prices to domestic prices, we estimate price pass-through elasticities and consider both perfect and imperfect price transmission from world to domestic Indian markets. We also estimate wage-price elasticities to assess how price changes are reflected in household wage incomes. Finally, the welfare effects through consumption and wage incomes are combined to determine the number of new poor created by the mandate. ${ }^{5}$

The main contribution of our paper is in using a partial equilibrium model for selected food crops to generate predictions for energy policy-induced commodity price shocks, and then using microlevel household data to study distributional effects at the household level. We incorporate uncertainty in the main parameters, and in the set of simulated prices to obtain the welfare and poverty effects using an econometric framework. Our poverty estimates are stochastic, not deterministic, as they reflect the uncertainty from Monte Carlo simulations. This approach enables us to understand how the decisions of an economy (the US) that is a major player in the world energy and food markets impact individuals and households in a developing country.

The surprising implication is that clean energy policies that raise food prices may have significant positive impacts in other nations where a large number of people work in the agricultural sector. The study is unique because there are almost no rigorous analyses of the global impacts of domestic energy or environmental policies using microdata. We show that domestic policy decisions of a major economy may have large global welfare impacts. ${ }^{6}$ In agricultural and energy markets, where the US produces (and consumes) a sizable share of world supply, these impacts may be significant, as we demonstrate in this paper. ${ }^{7}$

In Section 2, we outline the calibration model and obtain a distribution of price shocks for selected food commodities induced by the energy mandate. Section 3 discusses the framework for the welfare analysis, the data used, and estimates price passthrough elasticities of world to domestic Indian prices. Section 4 shows the welfare estimates. Section 5 concludes the paper.

\footnotetext{
${ }^{5}$ The methodology adopted in this paper is fairly general and can be used to study the distributional effects of any policy that causes food price shocks, for example, agricultural subsidies, trade barriers, or natural phenomena such as climate-induced droughts that affect crop yields.

${ }^{6}$ Leading economists from developing nations such as the former Indian Central Bank Governor, Raghuram Rajan, have pointed to the lack of economic studies that analyze the effect of US domestic policy on other nations.

${ }^{7}$ Specifically, there are almost no studies of US energy policy on other nations, using microlevel data that simulates the policy impact on individual households in a representative sample. See Bourguignon, Bussolo, and Pereira da Silva (2008) for a careful discussion of top-down models that use macroeconomic policies to study micro-level impacts. Another study (Bento, Goulder, Jacobsen, and Von Haefen (2009)) focuses on the impact of increased gasoline taxes on gasoline consumption and miles traveled in the US as well as the associated distributional effects across households that differ by income, race, and other characteristics.
} 


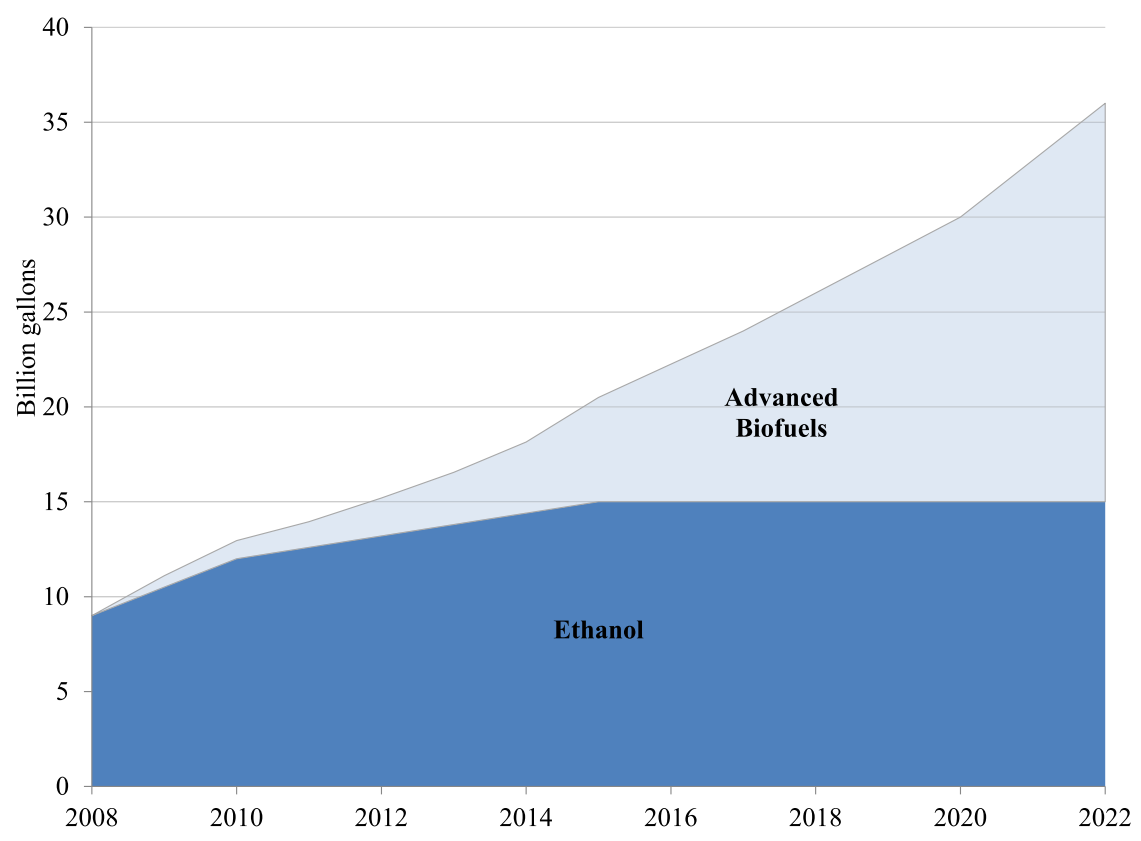

FiguRE 1. US renewable fuel mandate. Notes: Beyond 2015, the ethanol mandate is fixed at 15 billion gallons. The rest is advanced biofuels, mainly produced from biomass. Source: EPA (2010).

\section{IMPACT OF THE RFS ON FOOD PRICES}

In this section, we calibrate a simple, dynamic partial equilibrium model of the agriculture and transport sectors in order to trace the effect of the US Renewable Fuel Standard (RFS) on food prices. This mandate requires the use of biofuels (mainly from corn) in transportation to increase from the current 13 billion gallons to 36 billion by the year 2022 as shown in Figure $1 .^{8}$ First, we present a toy model which reveals the underlying economic principles, followed by a detailed specification of the calibration exercise. The goal is to show that the RFS will lead to a shift in land-use from agriculture to energy crops, thereby decreasing the supply of food crops and causing an increase in their prices. This in turn, will lead to new land being brought into cultivation, which has a dampening effect on prices.

\section{A model of energy and food}

Consider a partial equilibrium economy in which two goods are produced-transport energy and food crops. The quantity consumed of each good is denoted respectively by $q_{e}$ and $q_{f}$, where the subscripts $e$ and $f$ denote energy and food crops. ${ }^{9}$ Let the

\footnotetext{
${ }^{8}$ See https://www.epa.gov/renewable-fuel-standard-program/program-overview-renewable-fuelstandard-program for the program overview. There is some uncertainty as to how this ambitious mandate will be met by industry, especially in an era of low oil and gas prices; see CBO (2014).

${ }^{9}$ In the calibration model described below, we will distinguish food crops from food commodities. Demand is expressed in terms of the food commodity, for example, the rice crop is produced on land then
} 
downward-sloping inverse demand function for each good by denoted by $D_{j}^{-1}, j=\{e, f\}$. Demand is assumed independent of other goods. Transport energy is produced from gasoline or biofuel, which are assumed to be perfect substitutes. Food crops and biofuel are produced on land.

Land is assumed to be of uniform quality and may be allocated to energy or food production. ${ }^{10}$ Let $L_{j}(t), j \in\{e, f\}$, be the amount of land dedicated to producing energy and food at any time $t$. Since we use this model to predict future food prices, we explicitly incorporate model dynamics. The total land cultivated $L(t)$ is then given by $\sum_{j \in\{e, f\}} L_{j}(t)=L(t)$. Change in the total land area available under food or energy production equals the new land put to either use, defined by $l(t)$, that is, $\dot{L}(t)=l(t)$, where the dot represents the time derivative. Note that the variable $l(t)$ may be negative if land is taken out of production: here, we only allow for new land to be brought under cultivation.

The total cost of bringing new land into cultivation is increasing and convex as a function of aggregate land cultivated, but linear in the amount of new land used at any given instant. It is given by $c(L) l$, where we assume that $c^{\prime}(L)>0$ and $c^{\prime \prime}(L)>0$. The cost of conversion of land increases because it is likely to be remotely located and less accessible to markets. Thus the greater is the land area already under cultivation, the higher the unit cost of bringing new land into farming. The conversion cost function is the same whether the land is being used for food or energy.

Crop yield per unit of land for energy or food is denoted by $k_{j}$ where $j \in\{e, f\}$. Then the output of energy and food crops is given by $q_{e}=k_{e} L_{e}$ and $q_{f}=k_{f} L_{f}$, respectively, where we hide the time subscript. ${ }^{11}$ Total production cost is rising and convex with output $q_{j}$ and is given by $w_{j}\left(q_{j}\right)$.

The production of transport fuel is given by $k_{e} L_{e}+g$ where $k_{e} L_{e}$ and $g$ denote production of biofuels and gasoline. ${ }^{12}$ Let the unit cost of gasoline be $c_{g}$. The mandate is in the form of a quota and can be written as $k_{e} \bar{L}_{e}$ where $\bar{L}_{e}$ is the minimum land area required to meet the imposed target, giving us the constraint $k_{e} L_{e} \geq k_{e} \bar{L}_{e}$.

Let the social discount rate be $\rho$. Then we can write the constrained social planner's objective function as maximization of the discounted Marshallian surplus from energy and food by choosing how much land to plant to food and biofuels and the quantity of gasoline to be used as follows:

$$
\begin{gathered}
\operatorname{Max}_{\left\{L_{j}, l, g\right\}} \int_{0}^{\infty} e^{-\rho t}\left\{\left[\int_{0}^{k_{e} L_{e}+g} D_{e}^{-1}(\cdot) d \psi+\int_{0}^{k_{f} L_{f}} D_{f}^{-1}(\cdot) d \gamma\right]\right. \\
\left.-c(L) l-\sum_{j} w_{j}\left(k_{j} L_{j}\right)-c_{g} g\right\} d t, \quad j=\{e, f\}
\end{gathered}
$$

converted to rice commodity by applying a coefficient of transformation. In the theoretical model, this distinction is left out for tractability.

${ }^{10}$ The calibration model allows for heterogeneity in land quality across different geographical regions.

${ }^{11}$ Later, we allow for production of multiple food and energy crops.

${ }^{12}$ Here, we assume perfect substitution. In the calibration, gasoline and biofuels are considered imperfect substitutes and the production of crude oil and conversion to gasoline is explicitly modeled. 


$$
\begin{array}{ll}
\text { subject to } & k_{e} L_{e} \geq k_{e} \bar{L}_{e}, \\
& \sum_{j \in\{e, f\}} L_{j}(t)=L(t), \\
& \dot{L}(t)=l,
\end{array}
$$

The current value Lagrangian can be written as

$$
\begin{aligned}
L= & \int_{0}^{k_{e} L_{e}+g} D_{e}^{-1}(\cdot) d \psi+\int_{0}^{k_{f} L_{f}} D_{f}^{-1}(\cdot) d \gamma-c(L) l \\
& -\sum_{j \in\{f, e\}} w_{j}\left(k_{j} L_{j}\right)-c_{g} g+\theta k_{e}\left(L_{e}-\bar{L}_{e}\right) \\
& -\beta\left(\sum_{j \in\{e, f\}} L_{j}(t)-L(t)\right)-\lambda l,
\end{aligned}
$$

where $\theta$ is the multiplier associated with the mandate (2) and represents the implicit subsidy required to meet it, $\beta$ is the land rent, and $\lambda$ is the dynamic shadow price of land. The first-order conditions, assuming an interior solution, are given by

$$
\begin{aligned}
k_{e}\left(p_{e}+\theta-w_{e}^{\prime}\right)-\beta-c^{\prime}(L) l & =0, \\
k_{f}\left(p_{f}-w_{f}^{\prime}\right)-\beta-c^{\prime}(L) l & =0, \\
c(L)-\lambda & =0, \\
p_{e}-c_{g} & =0, \\
\text { and } \dot{\lambda}(t) & =r \lambda+c^{\prime}(L) l,
\end{aligned}
$$

along with associated nonnegativity constraints, not shown here. Condition (5) suggests that the price of energy $\left(p_{e}\right)$ equals the sum of the marginal cost of biofuel production $w_{e}^{\prime}$, the land rent $\beta$, and the marginal cost of land conversion $c^{\prime}(L) l$, both adjusted by crop yield minus the subsidy $\theta$ induced by the mandate. Equation (6) states that land is allocated to food production until the price of food $\left(p_{f}\right)$ equals the sum of the marginal cost of production $\left(w_{f}^{\prime}\right)$, the land rent $\beta$, and the marginal conversion cost $c^{\prime}(L) l$, both adjusted by crop yield. The dynamic shadow price of land $\lambda$ is equal to the marginal cost of land conversion from condition (7). Condition (8) suggests that the price of transport fuel equals the marginal cost of gasoline production. Since biofuels and gasoline are perfect substitutes, both are used in the production of transport fuel if and only if their marginal costs are equal. Finally, (9) relates the rate of change of the land shadow price to the discount rate and marginal cost of land conversion.

We can summarize the main insights from the model. Positive demand shocks will lead to higher prices for food or energy, and induce new land conversion, ceteris paribus. A higher price of gasoline will make biofuels relatively economical and trigger an acreage shift from food to energy. Food prices will rise, and new land conversion may occur, exerting a downward shift in prices. A larger biofuels mandate will implicitly mean a higher subsidy for biofuel production, increase land under biofuels, and lower consumption of the substitute, gasoline. 


\section{Model calibration}

In this section, we modify the simple analytical framework outlined above to calibrate a more realistic model that can trace the effect of the mandate on the price of selected food commodities in the world market. Specifically, we include heterogeneity in demand for energy and food in different geographical regions and differences in production costs and in land endowment and quality. The goal is to arrive at realistic long-run predictions for price increases for a set of food commodities that are critical to the Indian diet.

The price effects are modeled by considering three geographical regions-the United States, India, and the Rest of the World (ROW) - the last region aggregates all other nations. In the rest of the paper, we use the subscript $r$ for all parameters that are region-specific. We consider six food commodities-rice, wheat, corn, sugar, and "other food" which includes all other crops, and finally, "meat and dairy" are considered separately because they are not directly produced from land, although their production is land-intensive. ${ }^{13}$ A portion of the "other crops" and corn are used to feed animals which are then transformed into meat and dairy products. These six commodities are chosen for two reasons: their importance to the Indian diet and because they use significant land area globally, which makes them especially sensitive to acreage substitution induced by the mandate away from food to energy production. ${ }^{14}$ The "other food" category includes all grains other than rice, wheat, and corn such as starches and oil crops. ${ }^{15}$ The model assumes frictionless trading across the three regions in the food commodities, crude oil, and biofuels. However, transport fuel which is a blend of gasoline and biofuels, is assumed to be produced domestically in each region and is not traded.

Figure 2 shows a schematic of the calibration model. Land of different qualities is used to grow food crops and biofuels. Gasoline is produced from crude oil. Biofuels and gasoline are imperfect substitutes in transport fuel. The six food commodities and transport fuel are characterized by independent demand functions. The time-sensitive biofuel mandate is imposed as a consumption constraint that must be satisfied each year. The model is run for 100 years starting from base year 2012 with a discount rate of $2 \%$. All parameters are calibrated to match actual figures for year 2012.

Supply of food and biofuels As shown in Figure 2, each land class may produce the five food crops (rice, wheat, sugar, corn, and other food) and biofuels (first and second generation). ${ }^{16}$ Since land quality differs across different regions, we use the FAO-IIASA database (Fischer, Shah, Velthuizen, and Nachtergaele (2001)) to define three different land qualities based on soil and climate characteristics. Each quality is indexed by $n$ (high, medium, low) with high being the most productive. ${ }^{17}$ Total land area in the model

\footnotetext{
${ }^{13}$ On average, eight kilograms of cereals produce one kg of beef and three kgs produce one kg of pork.

${ }^{14}$ Rice, wheat, and sugar together supply $60 \%$ of all calories in India. They also consume large amounts of farmland-according to FAO (2016), rice and corn account for $11 \%$ and $12 \%$, respectively, of world farmland, and wheat another $14 \%$.

${ }^{15}$ These crops are not disaggregated further because they occupy a smaller acreage and are likely to be less important in terms of distributional effects in India than staples like rice, wheat, and corn.

${ }^{16}$ First generation biofuels are produced from corn in the US and from sugarcane in India and ROW.

${ }^{17}$ The database identifies four qualities—very suitable, suitable, moderately suitable, and marginally suitable. We have grouped these four into three, by consolidating the two intermediate classes into one, since their yield differences are small.
} 


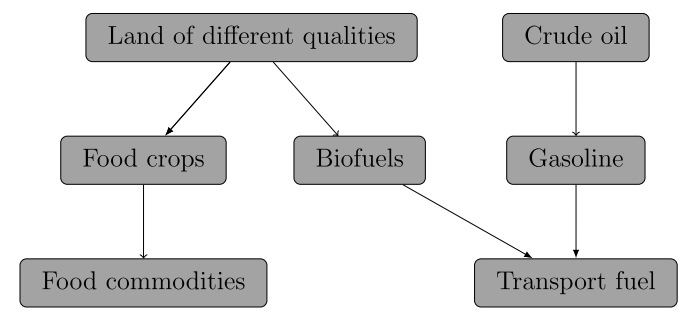

Figure 2. Schematic of the model with food and energy. Notes: Land of different qualities is used to produce either food crops (i.e., rice, wheat, corn, sugar, and "other crops") or biofuels. Food crops are then processed into food commodities. Transport energy is derived from gasoline and biofuels.

includes land cultivated in base year 2012 and fallow land that may be brought into cultivation in subsequent periods. Table 1 shows yields and endowment of land for the base year 2012 by land quality and region. ${ }^{18}$ We assume linear production, that is, output is yield times land area. For each land quality, the FAO/IIASA database has information on the acreage under each crop and its yield. ${ }^{19}$ The definition of land quality depends on the level of input use such as technology and irrigation. The FAO data gives yield estimates at various levels of inputs-high, medium, and low. For each crop and region, we match these yields to actual data from FAO (2016) for base year 2012 and choose the input level that matches the data. For the US, we adopt the yield for "high input" use, and for the other two regions, we choose the yield for "low input use." Yields can be three times higher on high quality land than on land of low quality. Since the model is dynamic, we allow for exogenous improvements in agricultural productivity specific to region and land quality. These annual growth rates are also shown in Table 1.

The total cost of producing a given crop in each region is a function of aggregate regional output and assumed to be increasing and convex. ${ }^{20}$ Let $j$ denote the crop produced on any given land, such as rice, wheat, corn, sugar, other crops, or biofuels. Then the total production cost for crop $j$ in a given region is defined as

$$
w_{j}^{r}\left(\sum_{n} k_{n}^{j r} L_{n}^{j r}\right)=\eta_{1}^{j r}\left[\sum_{n} k_{n}^{j r} L_{n}^{j r}\right]^{\eta_{2}^{j r}},
$$

\footnotetext{
${ }^{18}$ Protected forests are excluded from the model as in other studies (Golub, Hertel, and Sohngen (2009)). For India, we make the plausible assumption that no new land is available for farming (Ravindranath, Sita Lakshmi, Manuvie, and Balachandra (2011)).

${ }^{19}$ Crop acreage for US and India is readily available from this database. For the ROW region, we subtract the values for US and India from the total world figure. For wheat, rice, corn, and sugar, we can use the data directly. However, to obtain the yield per land class for the category "other crops," we calculate the weighted mean crop yield for grains, roots, tubers, pulses, and oil crops where the weight used is the share of each crop in total production in the region.

${ }^{20}$ Ideally, production costs should vary by land class. We have not followed this approach due to data limitations. The data base we employ to characterize the three land qualities has information on different crop yields and the area available per land class. However, there is no data on production costs.
} 
TABLE 1. Regional endowment of land (million ha) and crop yield (tons/ha) by land quality and region.

\begin{tabular}{|c|c|c|c|c|c|c|}
\hline Land Quality & Land Available & Rice & Wheat & Sugar & Corn & Other Crops \\
\hline & \multicolumn{6}{|c|}{ US } \\
\hline High & 60 & $7.1(1.20 \%)$ & $6.8(1.50 \%)$ & $86(0.02 \%)$ & $9.3(1.50 \%)$ & $4.5(1.20 \%)$ \\
\hline Medium & 80 & $5.1(1.20 \%)$ & $5.0(1.50 \%)$ & $72(0.02 \%)$ & $7.1(1.50 \%)$ & $3.5(1.20 \%)$ \\
\hline \multirow[t]{2}{*}{ Low } & 30 & $3.5(1.20 \%)$ & $2.9(1.50 \%)$ & $65(0.02 \%)$ & $4.7(1.50 \%)$ & $2.5(1.20 \%)$ \\
\hline & \multicolumn{6}{|c|}{ India } \\
\hline High & 70 & $3.2(1.20 \%)$ & $4.0(1.20 \%)$ & $79(0.01 \%)$ & $3.9(1.30 \%)$ & $2.0(1.20 \%)$ \\
\hline Medium & 60 & $2.8(1.20 \%)$ & $1.8(1.20 \%)$ & $60(0.01 \%)$ & $3.3(1.30 \%)$ & $1.5(1.20 \%)$ \\
\hline \multirow[t]{2}{*}{ Low } & 10 & $1.8(1.20 \%)$ & $1.5(1.20 \%)$ & $52(0.01 \%)$ & $1.9(1.30 \%)$ & $1.0(1.20 \%)$ \\
\hline & \multicolumn{6}{|c|}{ ROW } \\
\hline High & 200 & $4.0(1.20 \%)$ & $2.8(1.30 \%)$ & $70(0.01 \%)$ & $4.7(1.20 \%)$ & $2.2(1.50 \%)$ \\
\hline Medium & 650 & $3.0(1.20 \%)$ & $1.8(1.30 \%)$ & $60(0.01 \%)$ & $4.3(1.20 \%)$ & $1.8(1.50 \%)$ \\
\hline Low & 750 & $2.0(1.20 \%)$ & $0.8(1.30 \%)$ & $50(0.01 \%)$ & $2.6(1.20 \%)$ & $0.9(1.20 \%)$ \\
\hline
\end{tabular}

Note: Source: FAO-IIASA (2002) and FAO (2016). Numbers in parentheses represent the assumed annual growth rate of yield, calculated from historical data.

where $\sum_{n} k_{n}^{j r} L_{n}^{j r}$ is the aggregate output of product $j$, and $\eta_{1}^{j r}$ and $\eta_{2}^{j r}$ are crop-specific regional cost parameters. The values of the production cost parameters $\eta_{1}^{j r}$ and $\eta_{2}^{j r}$ obtained from GTAP 5 (1997) are shown in the Appendix Table A1. ${ }^{21}$

The price-induced conversion of new land to farming may vary by region. For example, an acre of land in a developing country may cost more to convert to farming than an acre in a developed nation which may have better infrastructure. The unit cost of conversion of land into farming for each land quality and region is taken from Sohngen and Mendelsohn (2003):

$$
c_{n}^{r}\left(L_{n}^{r}\right)=\psi_{1}^{r}-\psi_{2}^{r} \log \left(\frac{\bar{L}_{n}^{r}-L_{n}^{r}}{\bar{L}_{n}^{r}}\right)
$$

where $\bar{L}_{n}^{r}$ is the initial area of fallow land of quality $n$ available for cultivation in the base year and $L_{n}^{r}$ is the acreage of quality $n$ already cultivated. Thus, $\bar{L}_{n}^{r}-L_{n}^{r}$ is the residual land available. The smaller this value, the larger is the cost of conversion. Conversion costs go to infinity as available land gets exhausted, since very remote locations are prohibitively costly to develop. The parameters $\psi_{1}^{r}$ and $\psi_{2}^{r}$ are taken from Gouel and Hertel (2006) and reported in Table A2. These coefficients are the same for each land class but differ by region. We thus have three conversion cost functions for each region-one for each land quality.

Crops are transformed into six final food commodities (rice, wheat, corn, sugar, other food, and meat/dairy) by applying a constant coefficient of transformation. ${ }^{22}$

\footnotetext{
${ }^{21}$ Tables Al-A11 are in the Appendix in the Online Supplemental Material (Chakravorty, Hubert, and Marchand (2019)).

${ }^{22}$ For rice, wheat, sugar, and "other crops," we assume that one ton of crop produces 0.95 tons of the final food commodity (FAO (2016)), taken to be uniform across regions. A portion of "other crops" is used
} 
There are two types of biofuels in the model called first and second generation biofuels. The supply of first generation biofuels is region-specific, with a representative fuel for each region. This assumption is reasonable since only one type of first generation biofuel actually dominates in each region. For example, 93\% of US production in 2012 was from corn ethanol (EIA (2014)). In India, sugarcane ethanol is the main source of biofuel (Ravindranath et al. (2011)). The premier producer in the ROW region is Brazil where ethanol is also produced from sugarcane. Table A3 shows the representative crop for each region, its yield by land quality and production cost. ${ }^{23}$ Cellulosic or second generation biofuels are assumed to be only available in the US alone since it may take a while for them to acquire significant acreage in other regions. As these crops are less demanding in terms of land quality, we assume that their yield is uniform across different qualities (see Gelfand, Sahajpal, Zhang, Izaurralde, Gross, and Robertson (2013)). The yield of cellulosic ethanol is assumed to be 1, 800 gallons per hectare and its unit cost is \$1.1 per gallon (Chen, Huang, Khanna, and Önal (2014)).

Supply of transport energy Transport energy is supplied by gasoline and biofuels, which are imperfect substitutes. We adopt a CES specification as in Chen et al. (2014) given by

$$
q_{e}^{r}=\lambda^{r}\left[\mu_{g}^{r} q_{g}^{r^{\xi^{r}-1}}+\left(1-\mu_{g}^{r}\right)\left(q_{b f}^{r}+q_{b s}^{r}\right)^{\frac{\xi^{r}-1}{\xi^{r}}}\right]^{\frac{\xi^{r}}{\xi^{r}-1}},
$$

where $q_{e}^{r}$ is the production of transport fuel in the region $r, \mu_{g}^{r}$ is the share of gasoline in transport, $\xi^{r}$ is the elasticity of substitution, and $q_{g}^{r}, q_{b f}^{r}$, and $q_{b s}^{r}$ are the respective supplies of gasoline and first and second generation biofuels. The elasticity of substitution depends upon the technological barriers for displacing gasoline by biofuels. Elasticity estimates are from Hertel, Tyner, and Birur (2010), and the parameter $\lambda^{r}$ is a constant calibrated to reproduce the base-year production of transport fuel (see Table A4). ${ }^{24}$

Gasoline is produced from crude oil which is modeled as a competitive "bathtub" as in Nordhaus (2009). We posit a rising cost of extraction which captures the fact that with increased extraction, the unit cost of oil rises. ${ }^{25}$ As in Nordhaus, the unit extraction cost at any time $\tilde{t}$ is given by

$$
c_{o}(\tilde{t})=\phi_{1}+\phi_{2}\left(\frac{\sum_{t=1}^{\tilde{t}} \sum_{r} x^{r}(t)}{\bar{X}}\right)^{\phi_{3}},
$$

as animal feed. The quantity of meat and dairy produced from one ton of "other crops" (called feed ratio) is region-specific and adapted from Bouwman (1997). We use a feed ratio of 0.4 for US and 0.25 for India and ROW.

${ }^{23}$ Output of biofuel per hectare is computed as crop yield times the coefficient of transformation of the crop into biofuel. Production costs include the cost of transforming the crop into biofuel net the positive value of any by-products.

${ }^{24}$ The parameter $\lambda^{r}$ is a constant calibrated to reproduce base-year production of transport fuel, given by $\lambda^{r}=\frac{q_{e}^{r}}{\left[\mu_{g}^{r} q_{g}^{r} \frac{\xi^{r}-1}{\xi^{r}}+\left(1-\mu_{g}^{r}\right)\left(q_{b f}^{r}+q_{b s}^{r}\right)^{\frac{\xi^{r}-1}{\xi^{r}}}\right]^{\frac{\xi^{r}}{\xi^{r}-1}}}$ where $q_{e}^{r}, q_{g}^{r}, q_{b f}^{r}$, and $q_{b s}^{r}$ are at their 2012 levels. Data used to calibrate $\lambda^{r}$ is reported in Table A4. Supply of transport fuel, gasoline, and biofuels are taken from EIA (2014).

${ }^{25}$ These costs may rise due to depletion effects or the increased cost of environmental regulation of fossil fuels. 
where $x^{r}(t)$ represents the quantity of oil extracted in region $r$ at time $t$ and $\sum_{t=1}^{\tilde{t}} \sum_{r} x^{r}(t)$ the cumulative amount of oil extracted from date $t=1$ to $t=\tilde{t}, \bar{X}$ is the amount of oil available over the base year, and $\phi_{1}, \phi_{2}$, and $\phi_{3}$ are constant parameters. The parameter $\phi_{1}$ represents the unit extraction cost of oil over the base year, and $\phi_{1}+\phi_{2}$ the cost of extraction of the last unit (i.e., if the stock is completely exhausted). Data on the initial stock $(\bar{X})$, the parameters $\phi_{1}, \phi_{2}$, and $\phi_{3}$ are from Chakravorty, Magne, and Moreaux (2012) and reported in Table A5. According to IEA (2014), 64\% of global oil production is used in the transport sector, so we take the initial reserves to be $64 \%$ of world oil reserves, that is, 35.43 trillion gallons.

Crude oil is transformed into gasoline: one gallon of oil produces 0.47 gallons of gasoline. The cost of converting oil into gasoline is assumed to be the same across different regions and equals $\$ 0.46$ /gallon (Chakravorty, Hubert, Moreaux, and Nøstbakken (2017)). Since transport fuel demand is in energy units, we convert gallons into MegaJoules (MJ). A gallon of gasoline yields $120 \mathrm{MJ}$ of energy; a gallon of ethanol gives $80 \mathrm{MJ}$. Finally, transport fuel is transformed into Vehicle Miles Traveled (VMT): one MJ of transport energy equals 0.177 VMT for a gasoline-powered car (Chen, Huang, and Khanna (2012)).

Demand for food and transport energy Demands for each of the six food commodities and for transport fuel are modeled using generalized Cobb-Douglas functions. They are indexed by $i \in\{$ rice, wheat, corn, sugar, other food, meat/dairy, and transport fuel\}. Regional demand $D_{i}^{r}$ for good $i$ is given by

$$
D_{i}^{r}=A_{i}^{r} P_{i}^{r\left(\alpha_{i}^{r}\right)} y^{r\left(\beta_{i}^{r}\right)} N^{r},
$$

where $P_{i}^{r}$ is the price of good $i$ (in dollars), $\alpha_{i}^{r}$ and $\beta_{i}^{r}$ are the regional own-price and income elasticities for good $i, y^{r}$ and $N^{r}$ are regional per capita income in dollars per capita and population (in billions), and $A_{i}^{r}$ is the constant demand parameter calibrated from data (see Table A6) ${ }^{26}$ The constant $A_{i}^{r}$ is calibrated to reproduce demand in the base year and is calculated as $A_{i}^{r}=\frac{D_{i}^{r}}{P_{i}^{r\left(\alpha_{i}^{r}\right) y^{r}\left(\beta_{i}^{r}\right) N^{r}}}$ where $D_{i}^{r}, P_{i}^{r}, y^{r}, N^{r}$ are respectively, demand for good $i$, the price of good $i$, the GDP per capita in constant dollars and the population in the base year. These parameters used to compute $A_{i}^{r}$ for each commodity and region are shown in Table A6. Note that we impose exogenous population and GDP per capita projections for each region in order to capture time shifts in demand for food and energy. ${ }^{27}$

\footnotetext{
${ }^{26}$ Since there are no trade barriers for food commodities, in equilibrium, regional food prices are just world prices. However, transport fuel is produced domestically and not traded, therefore, fuel price varies by region.

${ }^{27}$ Data are obtained from the following sources: for own-price and income elasticities of transport fuel: Parry and Small (2005), Dimaranan, McDougall, and Hertel (2007); price and income elasticities of food commodities (US): Dimaranan, McDougall, and Hertel (2007), Regmi, Deepak, Seale, and Bernstein (2001), Regmi and Seale (2011), Muhammad, Seale, Meade, and Regmi (2011); price elasticities of food commodities (ROW): Roberts and Schlenker (2013) and Dimaranan, McDougall, and Hertel (2007); income elasticities for food commodities (ROW): Dimaranan, McDougall, and Hertel (2007); price and income elasticities of food commodities (India): Paul (2011), Dimaranan, McDougall, and Hertel (2007), Regmi et al. (2001),
} 
The RFS mandate sets a minimum use of first generation (ethanol from corn) and advanced biofuels as shown earlier in Figure 1. The consumption of first generation fuel equals 15 billion gallons in 2015 (EPA (2010)). Two categories of advanced biofuels are also specified in the mandate-4 billion gallons of low-carbon biofuels which must exhibit a 50\% reduction in greenhouse gas emissions relative to gasoline (only sugarcane ethanol from Brazil can meet this minimum requirement) and 16 billion gallons of second generation biofuels for the year 2022. We consider both types of advanced biofuels in the model. ${ }^{28}$

Using GAMS software, we run the model for two cases. In the BASE (baseline) model, biofuels are available but there is no RFS. In the REG (regulation) model, the RFS as explained above, is imposed. ${ }^{29}$ Specifically, we impose two constraints: (i) the minimum level of consumption of corn ethanol is set at 15 billion gallons in 2015, which can be met through domestic production or imports; (ii) and finally cellulosic production is set to increase to 21 billion gallons in 2022 .

The constrained social planner maximizes the discounted consumer plus producer surplus for all regions by choosing the allocation of land to food and biofuels and the consumption of gasoline. The mandate imposes a minimum use of biofuels for each year and causes grains to be diverted from food to energy. This leads to increased acreage in farming in regions that have large endowments of low-cost arable land. ${ }^{30}$

Validation of the model and effect on prices Before discussion model results, we assess its validity by proceeding in two steps. First, we check whether model predictions for the base year 2012 are reasonably close to observed values in the three regions. The results for consumption of food and fuel in US, India, and ROW are presented in Table A7, and world food prices are shown in Table A8. Both for consumption and prices, the tables show that model predictions are all within $10 \%$ of realized values.

Second, we check whether our model predicts the growth rate of prices during 20052012. We calibrate the model for 2005 in exactly the same fashion as was done earlier for $2012 .{ }^{31}$ It is run from 2005-2012. Since the objective of our study is to capture longrun behavior, we compare the average annual growth rate of food commodity prices

and Regmi and Seale (2011). For population, we use estimates from the United Nations (UNDP (2015)), specifically their medium range fertility projections which predict a 2050 world population of 9.3 billion. India's population is expected to increase to about 1.38 billion in 2022. Projections for GDP per capita are from EIA (2015); we adopt their intermediate oil price projection.

${ }^{28}$ Only the one billion gallon mandate for biodiesel that is part of the RFS is not included in our model. Since this is less than $3 \%$ of the total mandate, it will likely have a small effect on our results.

${ }^{29}$ India has also set a target for minimum use of biofuels of $20 \%$ by 2017 , however, the share of biofuels in transport fuel is less than 5\% and unlikely to rise sharply. We do not model this policy since the Indian biofuel policy will not likely impact world food and energy markets significantly_India consumes less than $2 \%$ of global transport fuel which is small compared to US consumption of about $40 \%$.

${ }^{30}$ Since we have made the model tractable by aggregating countries into three regions, we are unable to say precisely in which country (or countries) land conversion to farming occurs. That would require a more disaggregated framework and may be of limited interest for this study which focuses on the distributional impacts of RFS-induced price changes in one specific country.

${ }^{31}$ That is, we calculate the values of $A_{i}$ for each demand function, and the values of $\lambda$ for each region by using data for the new base year 2005. We use GDP for 2005 (in 2005 US dollars), and population. 
TABle 2. Price of food commodities (\$/ton) in 2022 with and without the biofuel mandate.

\begin{tabular}{lcccccc}
\hline & Rice & Wheat & Sugar & Meat & Corn & Other Food \\
\hline BASE & 514 & 501 & 456 & 2751 & 314 & 400 \\
REG & 556 & 580 & 458 & 3069 & 345 & 450 \\
\% diff & 8.17 & 15.77 & 0.44 & 11.56 & 9.87 & 12.50 \\
\hline
\end{tabular}

Note: BASE refers to the model without the mandate, and REG with it. \% diff refers to the percentage difference between the two prices.

during 2005-2012. Table A9 shows that predicted values from the model are within three percentage points of the observed value in all cases.

We first discuss the results using deterministic values for all parameters. Table 2 shows prices in year 2022 for the six food commodities with and without the mandate. ${ }^{32}$ The price effects are modest $(0-15 \%)$ relative to other studies (Roberts and Schlenker (2013), Hausman, Auffhammer, and Berck (2012)) possibly because of supply-side adjustments built into our model. ${ }^{33}$ Wheat prices increase the most followed by "other food" and meat and dairy. The price of wheat shows the largest increase as the US is a major wheat producer. Meat prices increase mainly due to the rise in the price of feed such as corn and soybean, which are a part of "other crops." Sugar prices are impacted less because it is mostly produced outside the US and can be cultivated in lower quality lands, unlike most grains. Relative to the no mandate case, the model predicts a shift in acreage away from food to energy production in the US of about 28 million hectares by the year 2022. This represents about $18 \%$ of US cropland. Since most of this additional land is released from the acreage in corn and "other crops," US production of food crops falls by about $32 \%$. Thus, net imports of food crops into the United States from ROW doubles. Indian net imports are not affected. India becomes a net importer of food crops in 2022 even under the BASE model, while it is almost self-sufficient in 2012. ${ }^{34}$

Next, we introduce stochastic distributions for parameters and perform Monte Carlo simulations to predict the outcome variables. This is our preferred approach because the parameter values (e.g., crop yields or the price of oil) may depend on external shocks, such as weather (e.g., hurricanes) or droughts. ${ }^{35}$ We proceed in two steps. First, we perform a sensitivity analysis to determine which model parameters have the greatest im-

\footnotetext{
${ }^{32}$ We show price estimates for the year 2022 because that is the terminal year for the RFS, and allows the model to make supply side adjustments. Recall that the goal of the paper is to estimate the effect of long-run price shocks on households. Short-run price shocks may be larger. We do not report the price of transport fuel because its mean share in Indian household expenditure is $0.3 \%$ for rural and $0.6 \%$ for urban households: welfare impacts are likely to be small. It is not included in the welfare estimations reported later.

${ }^{33}$ Our results are reasonably close to that of Scott (2013) who estimate that the US biofuels mandate leads to a $9.7 \%$ increase in prices in the aggregate. Our figures for wheat are a bit higher. Roberts and Schlenker (2013) reported higher price increases of about $20 \%$ with a $95 \%$ confidence interval of $14-35 \%$.

${ }^{34}$ We also ran the model by assuming that cellulosic yields vary with land quality, using an average growth rate across land classes as in other crops (see Table 1). Results suggest that cellulosic ethanol is produced on the lowest land quality; thus, more land is needed to meet the RFS target. The effect of the RFS on crop prices is slightly higher, for example, the difference in rice prices is $9.14 \%$ instead of $8.17 \%$ in Table 2 .

${ }^{35}$ As an example, after the 2012 drought in the US, average maize yields declined by $25 \%$ from their 2011 levels.
} 
pact on food prices. Then we assume stochastic distributions for these parameters in the simulations.

We shock the main model parameters: income elasticities for food and fuel, crop yields, extraction cost of crude oil and cost of biofuels (both ethanol and cellulosic), and the demand parameters: GDP per capita and population. The model is rerun by shocking each parameter one at a time, keeping the other parameters constant. To quantify the shock, Parry and Small (2005) assumed distributions for the parameters and defined a plausible range of parameter values to obtain a $90 \%$ confidence interval. We modify this approach by constructing a plausible range of parameter values using historical data (when available) or from other studies. From this data, we calculate the mean and standard deviation, and the shock applied to each parameter is set equal to the ratio of the absolute value of standard deviation to the mean.

The mean for the distribution of crop yield is just the mean yield for the base year. It varies by land quality and region, as reported in Table A10. ${ }^{36}$ The standard deviation of the distribution is computed from regional yield data for the period 1980-2010 obtained from FAO (2016). ${ }^{37}$ The base year unit cost for crude oil is also assumed to be the mean. The standard deviation is calculated from observed data from 1980-2010 (World Bank (2016)). For the parameters price elasticity of demand, income elasticity, cost of biofuel, GDP per capita, and population, we obtain plausible values from earlier studies. Their mean and standard deviation are reported in Table A10. ${ }^{38}$

Table 3 reports the results for the sensitivity analysis. In the top panel, we repeat the information from Table 2 to facilitate comparison. The lower panels show the price estimates and the difference between the regulated (BASE) and unregulated (REG) prices for each parameter shock. The figures in parentheses show the difference in percentage points between the price shocks for that panel relative to the model with initial parameter values (top panel). We use these differences to assess which parameter has the largest impact on prices from the mandate. For instance, the price of wheat increases with the mandate by $15.77 \%$ under the set of initial parameter values (see top panel on left) but with the higher food price elasticity, it increases by $13.28 \%$ (second panel). So, the difference is $-2.49 \%$ points, as noted in the last row of that panel. We then choose

\footnotetext{
${ }^{36}$ This data is readily available for rice, wheat, and sugar, both for US and India. For ROW, we net out India and US output from world production. For the "other crops" category, we calculate mean yield by dividing total production by acreage planted for each of the three regions.

${ }^{37} \mathrm{We}$ assume that extreme events affect all land classes equally. Since historical data on yield by land class is not available, we cannot compute standard deviations for each land quality. These are taken to be uniform, as shown in Table A10.

${ }^{38}$ Data on price and income elasticities for the US are from Dimaranan, McDougall, and Hertel (2007) and Regmi et al. (2001). Both studies estimate the elasticity for two groups of food commodities. The first group includes cereals, sugar and sugar cane, roots and tuber, oils seeds, vegetables, and fruits. We use this value as our common elasticity estimate for rice, wheat, sugar, and other food. Their second group of food commodities includes meat and dairy which we can adopt directly. Data on price and income elasticities for India are from Paul (2011), Dimaranan, McDougall, and Hertel (2007), and Mittal (2006). For the ROW region, we use elasticity data from Roberts and Schlenker (2013) and Dimaranan, McDougall, and Hertel (2007) by assuming that their world averages hold for ROW. Roberts and Schlenker (2013) estimated world elasticities for one consolidated commodity group that includes maize, wheat, rice, and soybeans, which we use for our four commodities: corn, rice, wheat, and other food.
} 
Table 3. Price of food commodities (\$/ton) with and without the mandate in 2022: sensitivity to parameters.

\begin{tabular}{|c|c|c|c|c|c|c|}
\hline & Rice & Wheat & Sugar & Meat & Corn & Other Food \\
\hline \multicolumn{7}{|c|}{ Initial parameter values } \\
\hline BASE & 514 & 501 & 456 & 2751 & 314 & 400 \\
\hline REG & 556 & 580 & 458 & 3069 & 345 & 450 \\
\hline$\%$ diff & 8.17 & 15.77 & 0.44 & 11.56 & 9.87 & 12.50 \\
\hline \multicolumn{7}{|c|}{ Price elasticity for food } \\
\hline BASE & 496 & 467 & 456 & 2615 & 301 & 378 \\
\hline REG & 530 & 529 & 457 & 2867 & 326 & 418 \\
\hline$\%$ diff & 6.85 & 13.28 & 0.22 & 9.64 & 8.31 & 10.58 \\
\hline & $(-1.32)$ & $(-2.49)$ & $(-0.22)$ & $(-1.92)$ & $(-1.57)$ & $(-1.92)$ \\
\hline \multicolumn{7}{|c|}{ Crop yield } \\
\hline BASE & 422 & 327 & 452 & 2052 & 244 & 288 \\
\hline REG & 448 & 375 & 454 & 2246 & 264 & 319 \\
\hline$\%$ diff & 6.16 & 14.68 & 0.44 & 9.45 & 8.20 & 10.76 \\
\hline & $(-2.01)$ & $(-1.09)$ & $(0.00)$ & $(-2.11)$ & $(-1.67)$ & $(-1.74)$ \\
\hline \multicolumn{7}{|c|}{ Income elasticity for food } \\
\hline BASE & 547 & 563 & 458 & 3001 & 339 & 440 \\
\hline REG & 594 & 645 & 460 & 3359 & 374 & 495 \\
\hline$\%$ diff & 8.59 & 14.56 & 0.44 & 11.93 & 10.32 & 12.50 \\
\hline & $(0.42)$ & $(-1.20)$ & $(0.00)$ & $(0.37)$ & $(0.45)$ & $(0.00)$ \\
\hline \multicolumn{7}{|c|}{ Per capita GDP } \\
\hline BASE & 552 & 571 & 458 & 3036 & 342 & 445 \\
\hline REG & 599 & 660 & 460 & 3391 & 378 & 502 \\
\hline$\%$ diff & 8.51 & 15.59 & 0.44 & 11.69 & 10.53 & 12.81 \\
\hline & $(0.34)$ & $(-0.18)$ & $(0.00)$ & $(0.13)$ & $(0.65)$ & $(0.31)$ \\
\hline \multicolumn{7}{|c|}{ Cost of land conversion } \\
\hline BASE & 638 & 735 & 461 & 3695 & 408 & 551 \\
\hline REG & 687 & 827 & 463 & 4062 & 444 & 609 \\
\hline$\%$ diff & 7.68 & 12.52 & 0.43 & 9.93 & 8.82 & 10.53 \\
\hline & $(-0.49)$ & $(-3.25)$ & $(-0.01)$ & $(-1.63)$ & $(-1.05)$ & $(-1.97)$ \\
\hline \multicolumn{7}{|c|}{ Unit cost of oil } \\
\hline BASE & 516 & 503 & 456 & 2760 & 315 & 401 \\
\hline REG & 557 & 581 & 458 & 3077 & 346 & 452 \\
\hline$\%$ diff & 7.95 & 15.51 & 0.44 & 11.49 & 9.84 & 12.72 \\
\hline & $(-0.22)$ & $(-0.26)$ & $(0.00)$ & $(-0.07)$ & $(-0.03)$ & $(0.22)$ \\
\hline
\end{tabular}

Note: BASE refers to the model without the mandate, and REG with it. Each parameter shock equals the ratio of its standard deviation to mean. \% diff is the difference in prices expressed as a percentage between BASE and REG. The numbers in parentheses show the contribution of the parameter (e.g., food price elasticity in the second panel) to the price shock. It is the difference in prices for that parameter and the initial values in the top panel.

the parameters that affect the price shocks the most. This involves comparison of the vector of price shocks for all six commodities in the table, along with some subjective judgment. The table shows that commodity prices are most sensitive to food price elasticities and crop yields, and less sensitive to other parameters. Rice and wheat are the most important crops, because of the acreage they occupy and their importance in the Indian diet, hence price changes for these two crops may have significant distributional 
effects. Using this criteria, we only focus on uncertainty in the two parameters listed in the top of the table, food price elasticity and crop yield. ${ }^{39}$

We next run the Monte Carlo simulations by modifying the calibration modelreplacing the two chosen parameters with their probability density functions. The parameter values for price elasticity and crop yields are assumed to be independent and normally distributed. The mean and standard deviation are shown in Table A10. We run the model at baseline and with the RFS, but this time with 500 randomly drawn values from the distributions of the two chosen parameters. This procedure yields 500 values for the vector of food prices with and without the mandate. The derived distribution of price changes is shown in Figure 3, plotted against the normal distribution. Note that the distributions are unimodal and close to normal, but skewed, especially for sugar, meat, and other foods, which point to the need to use the entire distribution in welfare analysis rather than their mean values. ${ }^{40}$ We only show the means and standard errors for the Monte Carlo simulations in Table 4 . The results suggest that impacts vary greatly across commodities, with $13.19 \%$ higher price for wheat and $7.87 \%$ for rice.

\section{ESTIMATION OF DISTRIBUTIONAL IMPACTS}

In this section, we estimate the distributional impacts of the mandate using micro-level surveys from India. We study changes in household welfare from the cost of consumption and wage incomes due to the increase in price for the six commodities. They are estimated with (REG) and without the mandate (BASE). The welfare impact is then defined as the percentage gain or loss to Indian households relative to the no RFS policy. The change in household welfare is given by the negative of the compensating variation as a share of initial household expenditure (Deaton (1989)). That is, the amount households must be compensated in order to have the same utility level they have without the RFS. After accounting for estimated changes in their wage incomes, we arrive at a net welfare effect for each household. We use the Monte Carlo results to estimate the standard errors for these welfare effects. This microlevel approach allows us to differentiate between households based on their characteristics such as expenditure patterns and factor endowments. This method has been used to investigate the impacts of price changes due to trade polices. ${ }^{41}$ However, our approach differs from these studies as it relies on stochastic outcomes of the Monte Carlo model, rather than deterministic values for policy variables such as tariffs. We obtain a distribution of welfare estimates for each household in the sample.

\footnotetext{
${ }^{39}$ The effect on sugar prices is generally low, since sugarcane can grow well on lower land qualities, unlike other crops (see Table 1). As a robustness check, we also ran the two models by shocking the remaining parameters such as income and price elasticity for transport, cost of biofuels and population. These shocks did not cause discernible price changes. We also applied $\mathrm{a}+/-30 \%$ shock to the mean value of each parameter. Our main results did not change.

${ }^{40}$ Values of the other parameters is assumed to be known with certainty. As a robustness check, we allow uncertainty in all parameters by assuming that they follow a normal distribution with mean and standard deviation as shown in Table A10. Results were similar.

${ }^{41}$ See, for example, Han, Liu, Marchand, and Zhang (2016), Nicita (2009), Porto (2010), Ural Marchand (2012), Ravallion (1990), and De Janvry and Sadoulet (2010).
} 

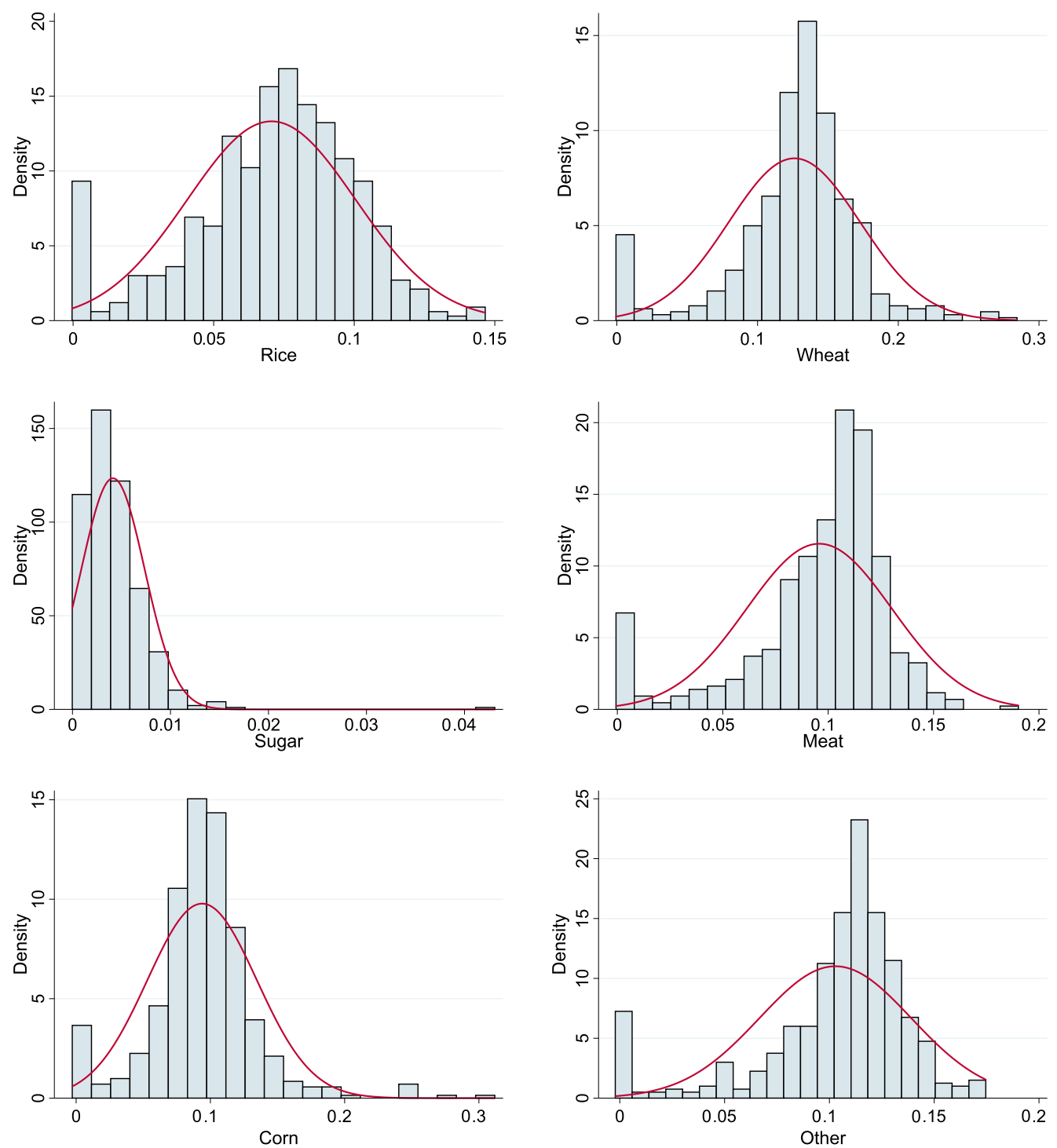

FIGURE 3. Distribution of commodity price shocks induced by mandate. Notes: The graphs show the distribution of price shocks for each commodity from 500 draws from the underlying parameter distributions with and without the RFS. We report values within two standard deviations of the mean, with less than 6 observations outside this range for each commodity. Smooth lines show the normal density.

Consider the following net expenditure function $B_{h}$ for a household denoted $h$ :

$$
B_{h}(p, u)=e_{h}(p, u)-w_{h}(p),
$$

where $p$ is the vector of prices, $e_{h}(p, u)$ is the expenditure required to reach utility level $u$, and $w_{h}(p)$ denotes the wage income of the household. A first-order Taylor series expansion of $B_{h}(p, u)$ around an initial price level $p^{0}$ and utility level $u^{0}$ and some manip- 
TABLE 4. Mean and standard error for food commodity prices in year 2022 with and without the mandate.

\begin{tabular}{|c|c|c|c|c|c|c|}
\hline & Rice & Wheat & Sugar & Meat & Corn & Other Food \\
\hline \multicolumn{7}{|c|}{ BASE } \\
\hline Mean & $\begin{array}{l}580 \\
(8.93)\end{array}$ & $\begin{array}{l}579 \\
(15.08)\end{array}$ & $\begin{array}{l}459 \\
\quad(0.45)\end{array}$ & $\begin{array}{l}3245 \\
\quad(67.31)\end{array}$ & $\begin{array}{l}358 \\
\quad(6.79)\end{array}$ & $\begin{array}{l}475 \\
(10.76)\end{array}$ \\
\hline \multicolumn{7}{|c|}{ REG } \\
\hline Mean & $\begin{array}{l}627 \\
(10.22)\end{array}$ & $\begin{array}{l}660 \\
(17.44)\end{array}$ & $\begin{array}{l}461 \\
\quad(0.42)\end{array}$ & $\begin{array}{l}3852 \\
(77.66)\end{array}$ & $\begin{array}{l}393 \\
\quad(7.56)\end{array}$ & $\begin{array}{l}530 \\
(12.35)\end{array}$ \\
\hline \multicolumn{7}{|c|}{ Change in commodity prices (\%) } \\
\hline Mean & $\begin{array}{c}7.87 \\
(0.76)\end{array}$ & $\begin{array}{l}13.19 \\
(0.36)\end{array}$ & $\begin{array}{c}0.39 \\
(0.009)\end{array}$ & $\begin{array}{c}9.44 \\
(0.25)\end{array}$ & $\begin{array}{c}9.89 \\
(0.69)\end{array}$ & $\begin{array}{l}10.88 \\
(0.51)\end{array}$ \\
\hline
\end{tabular}

Note: BASE refers to the model without the mandate, and REG with it. Standard errors are in parentheses. Mean and standard errors are obtained from 500 random draws from selected distributions of model parameters.

ulation yields

$$
d B_{h}(p, u)=B_{h}(p, u)-B_{h}\left(p^{0}, u^{0}\right)=\sum_{i}\left(\frac{\partial e_{h}}{\partial p_{i}}-\frac{\partial w_{h}}{\partial p_{i}}\right) d p_{i},
$$

where $d B_{h}(p, u)$ is the compensation the household needs to achieve the initial utility $u^{0}$. When this term is positive, it is a net transfer, hence a welfare loss for the household. When it is negative, the household is better off, thus experiencing a welfare gain. ${ }^{42}$ Define $W_{h}=-d B_{h}(p, u) / e_{h}$ as the compensating variation expressed as a fraction of household initial expenditure. ${ }^{43}$ Our estimating equation can then be written as

$$
W_{h}=-\sum_{i} \theta_{i h} d \ln p_{i}+\sum_{m} \sum_{i} \theta_{w_{i h}}^{m} \varepsilon_{w_{i}}^{s} d \ln p_{i}
$$

where $\theta_{i h}=x_{i h} p_{i} / e_{h}$ is the expenditure share of $\operatorname{good} i, \theta_{w_{i h}}^{m}$ is the share of wage income from production of good $i$ in the household budget contributed by member $m$, and $\varepsilon_{w_{i}}^{s}$ is the wage-price elasticity of individual $i$ with skill level $s$.

The terms on the right-hand side of (17) represent the different components of the compensating variation. The first term gives the direct consumption impact of the price change, $d \ln p_{i}$. Households that consume goods $i=1, \ldots, n$ will be impacted negatively due to an increase in their cost of consumption. The magnitude of this effect is proportional to the importance of these goods in their budget given by the budget shares $\theta_{i h}$. This share is computed for each household using survey data.

The second component of (17) measures the effect of the price shock on household income, which enters positively in their welfare function. These income changes

\footnotetext{
${ }^{42}$ Here, we assume that households are affected by the policy only through commodity prices.

${ }^{43}$ We can rewrite condition (16) as $W_{h}=-\frac{d B_{h}(p, u)}{e_{h}}=-\frac{1}{e_{h}} \sum_{i}\left(x_{i h} p_{i}-\varepsilon_{w_{i}} w_{i}\right) \frac{d p_{i}}{p_{i}}$ where $x_{i h}$ is the Hicksian demand for good $i$ by household $h$ and $\varepsilon_{w i}$ is the elasticity of wages with respect to the price of good $i$. By the envelope theorem, $\partial e_{h} / \partial p_{i}=x_{i h}$. Each member of the household contributes to household income, which is affected by the price change. We can express household wage income from good $i$ as $w_{i h}=\sum_{m} w_{i h}^{m}$ where $m=1, \ldots, M$ represents members of the household.
} 
are measured individually for each member $m$ and then aggregated up to the household. Individuals affiliated with industry $i$ with skill level $s$ experience an increase in their wages by the term $\varepsilon_{w_{i}}^{s} d \ln p_{i}$, where the wage-price elasticity $\varepsilon_{w_{i}}$ is estimated using employment survey data. ${ }^{44}$ The impact of wage income on household net expenditure is proportional to the contribution of member $m$ to the household budget, given by weight $\theta_{w_{i h}}^{m}$, which is computed using survey data. ${ }^{45}$

The compensating variation is estimated by commodity for each vector of price changes produced by the Monte Carlo analysis. This delivers a distribution of consumption impacts for each household, with mean $\hat{C}_{h}$ and standard error $\sigma_{C_{h}}$, wage impacts with mean $\hat{E}_{h}$ and standard error $\sigma_{E_{h}}$, as well as a total compensating variation with mean $\hat{W}_{h}$ and standard error $\sigma_{W_{h}}$. The total compensating variation can then be written as $^{46}$

$$
\hat{W}_{h}=\hat{C}_{h}+\hat{E}_{h}
$$

\section{Description of the survey data}

We use two nationally representative surveys from the National Sample Survey (NSS) of the Government of India-the Consumer Expenditure Survey to estimate the consumption component, and the Employment and Unemployment Survey for the earnings component of household welfare. The 61st and 66th rounds of these surveys, conducted during 2004-2005 and 2009-2010 are used. This is one of the richest micro-level surveys for a developing country as approximately 100,000 households and 460,000 individuals are surveyed in each of the 35 states of the country. Because the NSS samples rural and urban households separately, we distinguish between rural and urban welfare impacts.

The expenditure survey asks each household the value and quantity consumed for about 500 consumption items during the previous 30 -day period. ${ }^{47}$ The consumption goods are aggregated into commodity groups, namely rice, wheat, sugar, corn, meat, and "other foods" (see details in Table A11). The definitions of these six commodities are consistent across the calibration and econometric analysis in the paper. The "other food" category covers fruits, vegetables, starchy foods, other cereals, oil, and spices. The survey reports household consumption as "purchased" and "home produced." We only

\footnotetext{
${ }^{44}$ The terms good and industry are used interchangeably. However, we distinguish between the two in the next section. In particular, a good refers to consumption items in the household budget, and an industry refers to the individual's primary industry affiliation coded by the 5-digit Indian National Industry Classification (NIC), which includes detailed categories for agricultural goods.

${ }^{45}$ Household-level income data for profits, remittances, rents and transfers is not available, and thus not included in our analysis. These effects are likely to be small compared to the direct impacts through cost of consumption and wages. Second-order consumption effects are excluded. In a robustness check, these effects turn out to be quite small when estimated using cross and own-price elasticities from Regmi et al. (2001) and Dimaranan, McDougall, and Hertel (2007), respectively.

${ }^{46}$ This approach has the advantage of circumventing additional distributional assumptions on key parameters of the model. The econometric model incorporates the uncertainty from the Monte Carlo analysis.

${ }^{47}$ The 66th round reports consumption of meat, fruits, vegetables, and spices during a 7-day recall period. These expenditures are adjusted to 30 days.
} 
TABLE 5. Household mean expenditure shares (\%) by commodity.

\begin{tabular}{|c|c|c|c|c|c|c|c|c|c|c|c|c|}
\hline \multirow[b]{2}{*}{ Decile } & \multicolumn{6}{|c|}{ Rural } & \multicolumn{6}{|c|}{ Urban } \\
\hline & Rice & Wheat & Sugar & Meat & Corn & Other Food & Rice & Wheat & Sugar & Meat & Corn & Other Food \\
\hline 1 & 13.40 & 6.62 & 2.20 & 6.70 & 0.37 & 34.13 & 9.71 & 8.14 & 2.52 & 7.36 & 0.09 & 34.02 \\
\hline 2 & 10.83 & 6.13 & 2.36 & 9.49 & 0.25 & 33.36 & 8.88 & 6.61 & 2.41 & 9.59 & 0.03 & 32.39 \\
\hline 3 & 9.76 & 5.04 & 2.28 & 11.09 & 0.26 & 32.94 & 8.13 & 5.93 & 2.22 & 10.03 & 0.04 & 31.89 \\
\hline 4 & 8.82 & 4.60 & 2.29 & 12.02 & 0.20 & 32.12 & 7.57 & 5.18 & 2.13 & 10.97 & 0.03 & 31.22 \\
\hline 5 & 7.92 & 4.43 & 2.27 & 12.93 & 0.20 & 30.58 & 6.85 & 4.91 & 2.01 & 11.63 & 0.01 & 29.99 \\
\hline 6 & 7.25 & 3.89 & 2.14 & 12.92 & 0.10 & 30.61 & 6.26 & 4.26 & 1.85 & 11.74 & 0.01 & 29.16 \\
\hline 7 & 6.57 & 3.59 & 1.98 & 13.59 & 0.09 & 29.84 & 5.96 & 3.87 & 1.67 & 11.49 & 0.01 & 28.36 \\
\hline 8 & 5.66 & 3.10 & 1.85 & 13.45 & 0.08 & 28.60 & 5.01 & 3.26 & 1.46 & 11.01 & 0.01 & 28.43 \\
\hline 9 & 4.65 & 2.62 & 1.63 & 12.62 & 0.03 & 27.62 & 4.31 & 2.75 & 1.22 & 10.14 & 0.01 & 27.61 \\
\hline 10 & 2.72 & 1.61 & 1.02 & 8.53 & 0.03 & 25.70 & 2.51 & 1.71 & 0.76 & 7.71 & 0.00 & 24.22 \\
\hline Overall & 7.76 & 4.16 & 2.00 & 11.33 & 0.16 & 30.55 & 6.52 & 4.66 & 1.83 & 10.17 & 0.02 & 29.73 \\
\hline
\end{tabular}

Note: Mean monthly expenditure shares as a fraction of total expenditures are computed from the 2009-2010 round of the NSS Household Expenditure Survey. Deciles are based on household log per capita expenditure. Sampling weights are used.

use the "purchased" quantity as the price impacts are expected to mainly work through purchased goods. ${ }^{48}$

The mean household expenditure shares $\left(\theta_{i h}\right)$ computed from the 2009-2010 round of the expenditure survey are shown in Table $5 .{ }^{49}$ This is our baseline year for the welfare analysis. The distribution of household log per capita expenditure is divided into deciles and the mean shares are shown for both rural and urban households. The table shows that the budget share for food expenditures is higher for households at the lower end of the distribution. This is consistent with Engel's Law, which states that the budget share of food falls with income, even if food expenditures rise. Rural households in the lowest decile spend $13.4 \%$ of their budget on rice consumption, decreasing to about $2.7 \%$ for those in the highest decile. The distribution of budget shares for wheat, sugar, and "other food" follow a similar trend. We find an inverse-U shape in the budget share distribution for meat, indicating that meat consumption increases faster than income in the middle of the distribution.

For the wage income estimates, we use the employment survey, which is an individual-level labor market survey that has information about wages, labor supply, and occupation by 5-digit primary industry affiliation codes for each activity, reported according to the Indian National Industry Classification (NIC). The matching between the NIC codes and the product categories in the consumer expenditure survey is shown

\footnotetext{
${ }^{48}$ The NSS Consumer Expenditure survey includes rice and wheat purchases obtained through the Public Distribution System (PDS) at lower prices. A household which relies on the PDS will have lower expenditure shares of that commodity, and welfare effects from price changes will be correspondingly lower.

${ }^{49} \mathrm{We}$ assume homogeneous goods across households due to data restrictions. The type of grain consumed by each household may have distributional consequences. Imported products may be lower quality (domestic basmati rice is often considered superior to imported white rice) and less processed than the domestically produced variety, which would make distributional effects more regressive. Unfortunately, our survey data do not include product quality, or whether the household purchased an imported or domestic variety.
} 
TABLE 6. Employment shares (\%) for individuals by commodity.

\begin{tabular}{|c|c|c|c|c|c|c|c|c|}
\hline \multirow[b]{2}{*}{ Decile } & \multicolumn{4}{|c|}{ Rural } & \multicolumn{4}{|c|}{ Urban } \\
\hline & Grains & Sugar & Meat & Other Food & Grains & Sugar & Meat & Other Food \\
\hline 1 & 52.35 & 0.45 & 1.56 & 3.11 & 11.29 & 0.08 & 1.29 & 1.26 \\
\hline 2 & 47.34 & 0.54 & 1.82 & 3.17 & 11.57 & 0.08 & 1.52 & 1.22 \\
\hline 3 & 46.98 & 0.76 & 2.32 & 3.72 & 11.16 & 0.18 & 1.49 & 1.29 \\
\hline 4 & 45.67 & 0.76 & 2.32 & 3.72 & 10.24 & 0.24 & 1.80 & 2.77 \\
\hline 5 & 43.50 & 0.92 & 2.34 & 4.24 & 8.37 & 0.20 & 1.85 & 1.26 \\
\hline 6 & 41.26 & 1.05 & 2.66 & 4.64 & 7.44 & 0.06 & 1.89 & 1.45 \\
\hline 7 & 39.27 & 0.88 & 2.32 & 5.23 & 6.09 & 0.09 & 1.31 & 1.21 \\
\hline 8 & 35.03 & 1.46 & 2.80 & 5.72 & 4.92 & 0.24 & 1.67 & 0.99 \\
\hline 9 & 30.82 & 1.22 & 3.56 & 6.17 & 3.42 & 0.16 & 0.87 & 1.01 \\
\hline 10 & 25.27 & 0.68 & 3.42 & 6.35 & 2.08 & 0.08 & 0.68 & 0.68 \\
\hline Overall & 40.75 & 0.87 & 2.51 & 4.61 & 7.66 & 0.14 & 1.44 & 1.31 \\
\hline
\end{tabular}

Note: Grains denote all grains including rice and wheat: separate NIC codes for rice and wheat are not available. Employment shares as a fraction of total employment (including nonfood) are computed from the 66st round of the NSS Employment and Unemployment Survey. Deciles are based on household log per capita expenditure. The matching of the 5-digit NIC affiliation of workers to food categories is shown in Table A11. Sampling weights are used in the estimation.

in Table A11. The increase in the price of the six commodities affects the earnings of individuals engaged in their production, while the earnings of those not involved are assumed to stay unchanged. ${ }^{50}$

Table 6 shows the mean employment share of individuals (not households) in each industry obtained by aggregating across industry affiliations within households. The Indian NIC classification of industry affiliations of individuals does not distinguish between production of different types of grains (see Table A11), therefore, "grain" covers all grains including rice, wheat, and corn. As expected, a large share of rural individuals is employed in grain production. In the lowest decile, $52.4 \%$ of individuals report grain production as their primary industry, decreasing monotonically to about $25 \%$ in the highest decile. These shares are much smaller and range between $2 \%$ and $11.3 \%$ among urban individuals. The total share of individuals affiliated with food production is $48.7 \%$ in rural and $10.4 \%$ in urban areas.

The above stylized facts for expenditure and employment shares play an important role in the distributional effects of RFS policy. Consider a scenario with uniform price effects across commodities. In this case, the consumption impacts $\hat{C}_{h}$, would be higher (more negative) at the low end of the distribution due to the high budget share of food expenditures. On the other hand, the (positive) impact on wage income, $\hat{E}_{h}$ would also be higher for poorer households as a relatively high share of these individuals are in food production. The net compensating variation therefore depends on the relative size of these two channels. In terms of rural-urban differences, the consumption impact is expected to be similar between rural and urban households due

\footnotetext{
${ }^{50} \mathrm{We}$ do not measure general equilibrium impacts that arise from factor reallocation across industries. These effects are expected to be negligible due to strict labor market regulations, Besley and Burgess (2004), and low labor mobility across localities (Munshi and Rosenzweig (2009), Anderson (2011)).
} 
to their similar budget structures, while impacts on wage incomes are expected to diverge, with a higher effect among rural households. Note that the first-order price effects impact all households through the consumption channel, but the first-order income effect is accrued by workers in the directly affected sectors. Thus average consumption effects are larger in magnitude. The price effects of the RFS are nonuniform across commodities, which leads to additional variation in distributional impacts across households.

\section{Pass-through of world prices}

We need to worry about the extent to which world prices pass through to domestic Indian prices. India has a history of strong intervention in the form of agricultural subsidies and large-scale government procurement and distribution of food (see Kwiecinski and Jones (2010)). This regulatory environment may restrict the transmission of price shocks from world to domestic markets. Even with no government regulation, price transmission may be low due to other distortions, such as imperfectly competitive producers or retailers, as well as imperfect substitution between imported and domestic goods. ${ }^{51}$

We thus consider both perfect and imperfect pass-through of world prices. ${ }^{52}$ For the latter, pass-through elasticities for each commodity are estimated using monthly time-series data. The estimates rely on the period 2005-2011, as prior data is not available. This period is somewhat unusual because of the spike in commodity prices in 2008, shown in Figure 4, and the resulting aggressive short run response by the Indian government. ${ }^{53}$ Due to data limitations, it is not possible to identify the transmission mechanism independent of this policy response. However, even though government intervention may have mitigated the effect of world price shocks in the short-run (as is clear from the figure), they are distortionary, and hence potentially costly in the long run. ${ }^{54}$

\footnotetext{
${ }^{51}$ Public distribution of food at lower than retail prices will reduce pass-through. In the exchange rate pass-through literature, Gopinath and Burstein (2014) among others, show that competition among retailers is a key determinant of pass-through rates.

${ }^{52}$ The Monte Carlo simulations assume perfect transmission in all regions, as it is not possible to incorporate market imperfections for the ROW category, which includes many countries. Instead, we introduce market imperfections for India in the econometric model, and present results for both perfect and imperfect pass-through of world prices. Welfare estimations are static in the sense that they compare a cross-section of households with different consumption baskets. In other words, we are shocking households once all the long term adjustments have taken place which includes the domestic price adjustments through the pass-through mechanism.

${ }^{53}$ India implemented several temporary measures during this time. These include trade policies (export bans, minimum export prices, export taxes, and temporary removal of tariffs), increasing minimum support prices, delisting crops from futures trading, and creating and releasing strategic food reserves. Some of these measures were in effect only for a few months, but they were largely effective in insulating the domestic market from price increases during the crisis (Kwiecinski and Jones (2010)). Most of these policies were removed eventually.

${ }^{54}$ These costs are not included in our estimates.
} 

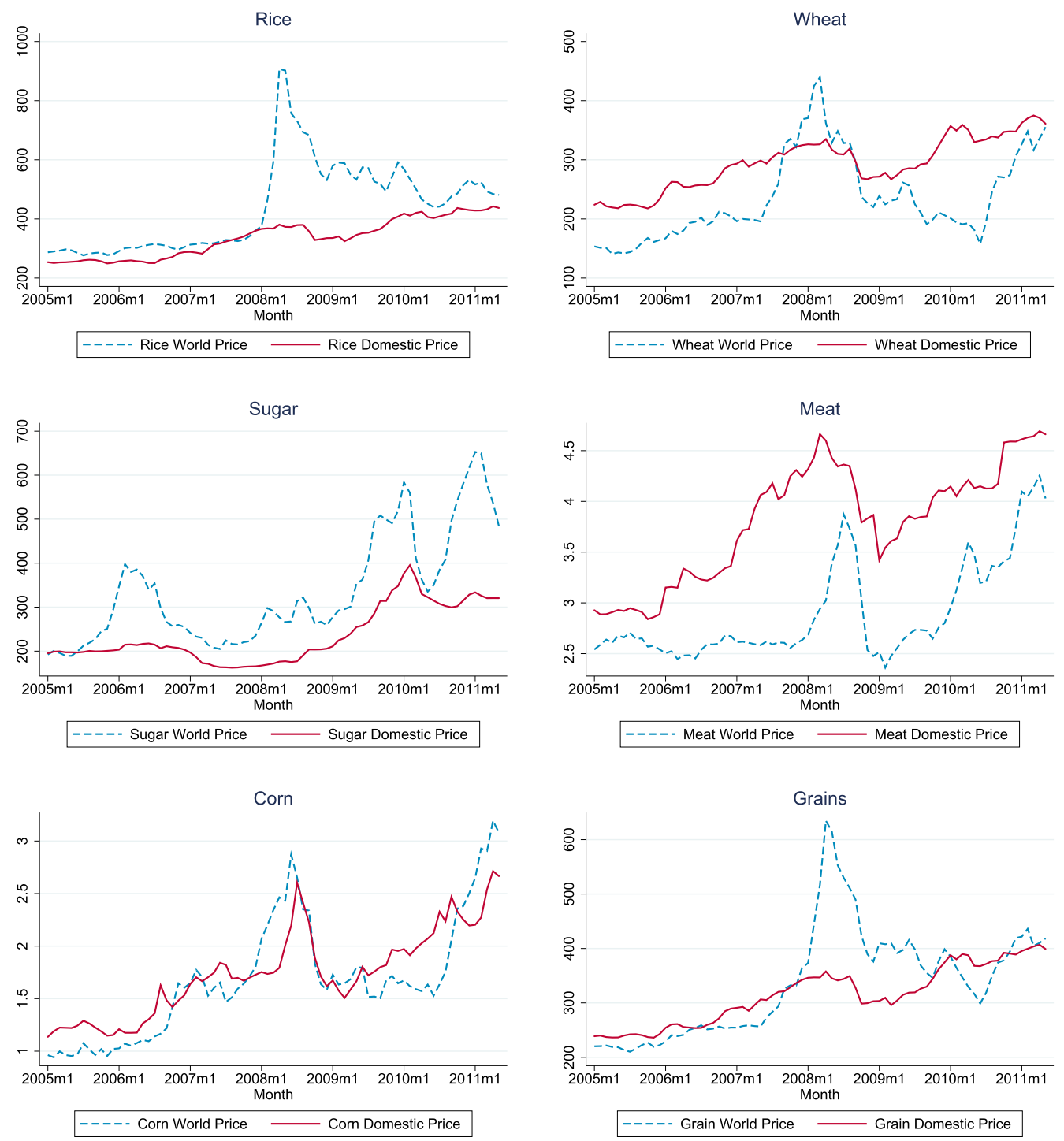

Figure 4. Domestic and world prices (\$) for food commodities. Notes: All prices are in current US dollars. Rice, sugar, wheat, and grain prices are in metric tons, while meat and corn prices are in kilograms. Grains include rice and wheat.

Domestic prices for rice, wheat, and sugar are obtained from the Indian Ministry of Public Affairs. They reflect average end-of-month prices across different zones of India. ${ }^{55}$ Corn prices are end of month spot prices from the Indian National Commodity and Derivatives Exchange. Meat prices are obtained from the Indian Ministry of Agri-

\footnotetext{
${ }^{55}$ The Indian Ministry of Public Affairs collects price data from the Northern, Western, Eastern, Northeastern, and Southern zones which are then averaged to obtain a nationwide price level for each commodity.
} 
TABLE 7. Percent increase in commodity prices, 2005-2011.

\begin{tabular}{lrrrrrr}
\hline & Rice & Wheat & Sugar & Meat & Corn & Grains \\
\hline Domestic & 72.29 & 61.16 & 64.11 & 59.16 & 184.62 & 67.07 \\
World & 67.74 & 131.31 & 151.72 & 74.33 & 219.84 & 89.90 \\
Ratio & 1.07 & 0.47 & 0.42 & 0.80 & 0.84 & 0.75 \\
\hline
\end{tabular}

Note: Ratio represents domestic over world price. The price series are converted to US dollars using exchange rates from the Reserve Bank of India. The period January 2005-May 2011 is the longest available for all commodities. Grains include rice, wheat, and corn and its pass-through elasticity is used to compute wage impacts.

culture. ${ }^{56}$ Grain prices are defined as the average of rice and wheat prices, as consistent domestic and world prices for grains are not readily available. ${ }^{57}$ Exchange rates are obtained from the Federal Reserve Bank of India. All world prices are taken from the World Bank Commodity Price database. ${ }^{58}$

Table 7 shows the summary statistics for price changes for the major commodities between January 2005 and May 2011. Domestic price changes for rice, corn, and meat were similar to changes in the world price, with growth rates of $1.07,0.8$, and 0.84 percent, respectively. However, wheat and sugar prices grew at a slower rate in the domestic market compared to the world price, also seen in Figure 4. Movements in world prices transmitted only partially to the domestic market, suggesting that pass-through coefficients are likely to vary across commodities and need to be estimated individually.

We estimate these pass-through elasticities using a single equation framework, as in Campa and Goldberg (2005) and Campa and Gonzalez Minguez (2006). ${ }^{59}$ The estimating equation is

$$
\Delta \ln p_{t}^{d}=\sum_{k} \beta_{k} \Delta \ln p_{t-k}^{w}+\gamma \Delta \ln \left(1+\tau_{t}\right)+\delta \Delta \ln e_{t}+\varepsilon_{t},
$$

where $p_{t}^{d}$ is the domestic price vector expressed in local currency (rupees) for month $t$; $k$ denotes the set of lags where $k=0,3,6,9$, and 12; $p_{t}^{w}$ is the world price, $\tau_{t}$ is the tariff

\footnotetext{
${ }^{56}$ Average meat (mutton) prices are for Hyderabad, Gujarat, Karnataka, Orissa, Maharashtra, Delhi, Tamil Nadu, Uttar Pradesh, and West Bengal. The 2010 and 2011 prices are extrapolated using the wholesale price index for meat.

${ }^{57}$ The pass-through elasticity for grains is needed to estimate wage impacts under imperfect passthough.

${ }^{58}$ For rice prices, the Thai 5\% variety is used, as it provides the longest series. US Hard Red Winter (HRW) prices are used for wheat.

${ }^{59}$ There are other approaches to measuring the pass-through, for example, De Janvry and Sadoulet (2010) interpreted it as the ratio of growth rates in domestic and world prices. Following their approach, we find a $107 \%$ pass-through elasticity for rice and $47 \%$ for wheat. However, this method does not control for factors such as trade policy shocks. Mundlak and Larson (1992) estimate a model in levels instead of differenceswe find higher and significant elasticities for all commodities using their approach. This is not appropriate in our case, however, since the augmented Dickey-Fuller tests suggest that the price series are integrated of degree one and, therefore, the pass-through coefficients estimated on levels may reflect arbitrary correlation between the series. In addition, the Johansen test suggests that we cannot reject the null hypothesis of no cointegration for most of our series.
} 
TABLE 8. Estimation of price pass-through elasticities.

\begin{tabular}{lcc}
\hline & Short Run $\left(\beta_{1}\right)$ & Long Run $\left(\sum \beta_{i}\right)$ \\
\hline Rice & 0.057 & 0.181 \\
& $(0.021)$ & {$[7.97]$} \\
Wheat & 0.008 & 0.006 \\
& $(0.035)$ & {$[0.01]$} \\
Sugar & 0.219 & 0.383 \\
& $(0.043)$ & {$[16.40]$} \\
Meat & -0.023 & 0.056 \\
& $(0.068)$ & {$[0.06]$} \\
Corn & 0.280 & 0.197 \\
& $(0.093)$ & {$[19.66]$} \\
Grains & 0.069 & 0.184 \\
& $(0.024)$ & {$[5.62]$} \\
\hline
\end{tabular}

Note: Standard errors for short run elasticities are reported in parenthesis and $F$-statistics for long-run elasticities are in square brackets. Grains include rice and wheat and its pass-through elasticity is used to compute wage impacts. Only the significant long-run elasticities are incorporated in the estimation.

rate for the commodity, $e_{t}$ is the exchange rate and $\varepsilon$ is an i.i.d. error term at time $t$. Prices are expressed in nominal terms.$^{60}$ Because our goal is to estimate the distributional effects in the long run, we estimate the long-run pass through elasticities by including the contemporaneous change in world prices, $\Delta \ln p_{t}^{w}$ as well as the quarterly lags in the model, $\Delta \ln p_{t-k}^{w}$ where $k$ denotes the lag for each quarter. ${ }^{61}$ The short term elasticity is thus given by the coefficient on the contemporaneous price level $\beta_{0}$, while the longterm elasticity $\sum_{i=0}^{12} \beta_{i}$ is defined as the sum of the coefficients on contemporaneous and lagged prices.

Table 8 shows that the short run transmission of rice prices is statistically significant, although the magnitude of the pass-through transmission elasticity is relatively small. A 100\% increase in the world price of rice yields a 5.7\% increase in the domestic price in the short run. Sugar and corn elasticities are also significant and larger in magnitude. Pass-through elasticities for meat and wheat are insignificant.

The welfare impacts under imperfect pass-through are estimated by incorporating the long-run pass-through elasticities. Based on Table 8, world price shocks for rice, sugar, and corn are transmitted by $18.1 \%, 38.3 \%$, and $19.7 \%$, respectively, while changes in wheat and meat prices are not reflected in the domestic market. The predicted price effects from Figure 3 are multiplied by these pass-through elasticities prior to the estimation of welfare effects. ${ }^{62}$ The domestic price can be written as $d \ln p_{i, \text { imp }}=\varepsilon_{i, \text { imp }} * d \ln p_{i}$

\footnotetext{
${ }^{60}$ Results are similar when prices are expressed in dollars and the exchange rate variable is dropped. In addition, Granger-Wald tests suggest that there is no reverse causality from domestic to world prices for any of the commodities.

${ }^{61}$ Given the length of our data series, it is not possible to consistently estimate the model with all 12 lags, hence we choose quarterly lags.

${ }^{62}$ For the "other food" category, the pass-through elasticity is taken as unity.
} 
where $\varepsilon_{i \text {,imp }}$ is the pass-through elasticity from Table 8 . In the analysis with perfect passthrough assumption, world prices are assumed to perfectly transmit to the domestic market, thus $\varepsilon_{i, \text { imp }}$ equals unity.

\section{Estimation of wage-price elasticities}

The response of wage incomes to price shocks is given by $w=w(p, \gamma)$ where $p$ is the vector of commodity prices and $\gamma$ is a set of personal characteristics such as education, age, marital status, or location. According to the Indian Ministry of Statistics (MOSPI), the informal sector accounts for about $90 \%$ of the workforce and $50 \%$ of the national product (MOSPI (2012)). A major advantage of the NSS Employment and Unemployment Survey is that it includes both formal and informal sector labor. Because we aim to estimate the total welfare impacts, the analyses are conducted based on cash and kind weekly wage incomes as reported in the survey. We focus on the working age population between 15 and 65 years old. The sample is restricted to workers with a principal industry affiliation in one of the six product categories. ${ }^{63}$ The model is estimated separately for skilled and unskilled workers, where an unskilled individual is defined as someone who is illiterate.

We exploit district variation in prices over time and estimate the following wage equation:

$$
\ln w_{k d t}=\alpha+\beta \ln p_{d t}+\delta \gamma_{k d t}+\mu_{s t}+\varepsilon_{k d t},
$$

where $w_{k d t}$ is the wage income of individual $k$ in district $d$ at time $t ; \beta$ is the wage-price elasticity; $\ln p_{d t}$ is the price level in district $d$ at time $t$, and $\gamma_{k d t}$ is a vector of individual characteristics that includes age, age-squared, and indicator variables for male and married workers; $\mu_{s t}$ is the interaction of state and year fixed effects, and $\varepsilon_{k d t}$ is an i.i.d. error term. ${ }^{64}$

The unit prices of products are based on the two rounds of the NSS Consumer Expenditure Survey. We use the value and quantity of the commodities reported by each household to arrive at a price variable at the household level. ${ }^{65}$ We then compute the average price within each district for each of the six commodities across years, using sampling weights to ensure that the sample is representative of the district. Next, we merge these six district level price variables with the corresponding rounds of the NSS Employment and Unemployment Survey, where we compute the employment shares of individuals who work in the production of these commodities. We then obtain the following weighted average of district level prices using the employment shares in the initial round as weights $p_{d t}=\sum_{i}\left(\chi_{i d, 2005}\right) p_{i d t}$ where $\chi_{i d, 2005}$ is the employment share of product $i$ in district $d$ in 2005 from the Employment Survey, and $p_{i d t}$ is the district level unit price for each product from the Consumer Expenditure Survey. This variable

\footnotetext{
${ }^{63}$ Following common practice, the 5-digit NIC code for the "usual principal activity" variable is used as the principal industry affiliation of each individual (Table A11).

${ }^{64}$ Using geographical variation is common. Deaton (2000) exploited the regional variation in prices to estimate systems of demand parameters and Ravallion (1990) and Porto $(2006,2010)$ used consumption surveys to exploit time variation in prices to estimate wage responses. Jacoby (2016) also estimated wageprice elasticities across districts using changes in wages over time.

${ }^{65}$ The producer prices for these commodities are unfortunately not available at the district level.
} 
reflects the importance of each sector within each district. The weights are fixed in the initial year to ensure that $p_{d t}$ does not reflect the selective sorting of product-specific employment over the sample period.

We are interested in the response of wage incomes to exogenous changes in prices among rural and urban households across the skill distribution. In order to account for unobservable factors correlated with wages that vary over time within states, the specification includes a vector of state and year interactions. While the inclusion of these interaction terms alleviates many endogeneity concerns, the time varying unobservable factors at the district level that are correlated with price levels and wage incomes may bias the estimates. For example, differential improvements in technology across districts may raise wage incomes due to the high value of marginal product of labor, and may influence prices if the new technology leads to a higher quality product. There may also be spatially correlated shocks across districts that affect both wages and prices (Jacoby (2016)).

In order to identify the effect of exogenous changes in prices, we use an identification strategy based on exogenous changes in prices as an instrument. Specifically, we construct a price variable which uses the employment weights in all districts within a state, excluding the district in which the worker is located. Unlike the variation in prices, this measure is driven by aggregate shocks and is thus orthogonal to factors that might directly influence prices in each district. ${ }^{66}$ It is given by $\bar{p}_{d t}=\sum_{i}\left(\chi_{i d^{-}, 2005}\right) p_{i d t}$ where $\chi_{i d^{-}, 2005}$ is the employment share of product $i$ in 2005 in all districts except the owndistrict.

Table 9 shows the estimation results. The rural wage-price elasticity under OLS is estimated as 0.14 for unskilled and 0.15 for skilled individuals, both statistically significant. The elasticities identified through IV are higher than the OLS elasticities- 0.2 for unskilled and 0.29 for skilled individuals in rural areas. For urban workers, only unskilled wage incomes respond significantly to price changes in the IV estimation, with an elasticity of 0.2 , while the estimate is insignificant for skilled workers. ${ }^{67}$

One consideration is that labor mobility across districts may violate the exclusion restriction of the instrument. India has exceptionally low labor mobility across geographical regions due to strong social ties in communities (Munshi and Rosenzweig (2009)). Caste-based networks provide social insurance in the absence of well-functioning insurance markets. These networks tend to significantly reduce mobility rates. Anderson (2011) noted that there is virtually no mobility among castes. In most studies, the rural population is assumed to be essentially immobile, as a tiny share of individuals report that they have left their village of birth (Munshi and Rosenzweig (2009)). As a result,

\footnotetext{
${ }^{66}$ Similar instruments are often used in the literature. For example, in order to estimate wage-price elasticities in rural India, Jacoby (2016) used crop area-weighted prices in all states except the state to which the district belongs. Mazzolari and Ragusa (2013) used the employment-weighted share of wages in US cities other than the own-city as an instrument to estimate the effect of consumption spillovers on employment.

${ }^{67}$ As an alternative approach, we use international prices for the commodities as an instrument for domestic prices as in Porto (2010). This regression yields insignificant elasticities for rural individuals, and larger elasticities for urban residents. In our case, this is not our preferred approach for two reasons. First, world prices may not be entirely excludable for a large country such as India. Second, there is little variation in world prices as they do not exhibit variation across districts.
} 
TAвle 9. Estimation of wage-price elasticities.

\begin{tabular}{|c|c|c|c|c|}
\hline & \multicolumn{2}{|c|}{ Rural } & \multicolumn{2}{|c|}{ Urban } \\
\hline & OLS & IV & OLS & IV \\
\hline \multicolumn{5}{|l|}{ Unskilled } \\
\hline Wage-price elasticity & $\begin{array}{c}0.141 \\
(0.031)\end{array}$ & $\begin{array}{c}0.195 \\
(0.105)\end{array}$ & $\begin{array}{c}0.263 \\
(0.056)\end{array}$ & $\begin{array}{c}0.204 \\
(0.120)\end{array}$ \\
\hline$R^{2}$ & 0.440 & 0.439 & 0.521 & 0.512 \\
\hline$N$ & 14,348 & 14,307 & 1291 & 1283 \\
\hline Kleibergen-Paap $p$-value & & 0.0001 & & 0.0002 \\
\hline First stage F-stat & & 55.856 & & 15.738 \\
\hline \multicolumn{5}{|l|}{ Skilled } \\
\hline Wage-price elasticity & $\begin{array}{c}0.154 \\
(0.030)\end{array}$ & $\begin{array}{c}0.289 \\
(0.130)\end{array}$ & $\begin{array}{c}0.238 \\
(0.061)\end{array}$ & $\begin{array}{c}0.009 \\
(0.209)\end{array}$ \\
\hline$R^{2}$ & 0.361 & 0.355 & 0.424 & 0.369 \\
\hline$N$ & 14,498 & 14,405 & 1749 & 1720 \\
\hline Kleibergen-Paap $p$-value & & 0.0004 & & 0.0007 \\
\hline First stage F-stat & & 22.681 & & 14.696 \\
\hline
\end{tabular}

Note: An unskilled individual is defined as someone who is illiterate. Estimates based on wage income of individuals and unit prices from the NSS Consumer Expenditure Survey. Employment-weighted price levels are used. All regressions control for age, age-squared, gender, marital status, and interaction of state and year fixed effects. Standard errors are clustered at the district level.

migration in India is very low compared to countries at similar levels of development (Anderson (2011)).

The smaller wage response for rural unskilled workers is consistent with reported wage rigidities in the agricultural sector. Dreze and Mukherjee (1989) in their analyses of Indian rural labor markets observe that the standard wage often applies for prolonged periods of time, from several months to years. They observe little seasonality and note that casual wages are rigid downwards during slack seasons. Supreet (2014) showed that wages in India are rigid, which leads to unemployment once the positive shock dissipates. Our estimated elasticities are similar in magnitude to those reported for countries that are at similar stages of development. Datt and Olmsted (2004) found the short term wage-food price elasticity for Egypt to be 0.27 , while Boyce and Ravallion (1991) reported the short-run wage elasticity with respect to the price of rice in Bangladesh to be 0.22 . The insignificant response of skilled wages for urban workers is expected since these workers tend to be affiliated with food manufacturing rather than direct production in the agricultural sector.

\section{Household WELFARE AND POVERTY impaCtS}

In this section, we present the estimates for consumption, income and net welfare effects on households. First, we present the results under perfect pass-through followed by imperfect pass-through where we apply the elasticities from (8). We show results across the per capita expenditure distribution for rural and urban households. The decile-level averages for consumption effects $\hat{C}_{h}$, and their standard errors, $\sigma_{C_{h}}$ are presented in the top panel of Table 10. Under perfect pass-through, households in the lowest decile suffer 
a welfare loss of about $6 \%$ through the consumption channel. This loss monotonically decreases to about $4 \%$ at the highest decile. Losses are slightly higher for urban households in the lower five deciles, and higher for the upper five deciles. Since budget shares are similar for rural and urban households, welfare effects are also of similar magnitude. Under imperfect pass-through, all effects decline in magnitude. Rural households at the lowest decile experience a $4 \%$ loss, decreasing to $2.6 \%$ at the highest decile. These figures are similar for urban households.

Figure 5 plots the local polynomial regressions for household-level consumption effects on log per capita expenditure. The positive slopes suggest that consumption effects are regressive, that is, households at the lower end of the distribution experience larger welfare losses. They are smaller under imperfect pass-through. However, the difference between perfect and imperfect pass-through is more pronounced at the lower end of the distribution because the budget shares of the commodities are larger for these households.

Wage income effects, $\hat{E}_{h}$, and their standard errors, $\sigma_{E_{h}}$, are shown in the second panel of Table 10. Under perfect pass-through, rural households at the lowest decile experience a $7 \%$ welfare gain. This is because a large share of these households is employed in food production. These gains decline sharply with household expenditure, to only $0.15 \%$ for households in the highest decile. Among urban households, the magnitude of these welfare gains is much smaller everywhere in the distribution, mainly due to the low share of individuals employed in food industries. Under imperfect passthrough, gains from wage income are still progressive, but lower in magnitude due to smaller price effects.

Figure 6 shows that the distribution of welfare effects through wage incomes has a negative slope for both rural and urban households, suggesting that wage income effects are progressive. As expected, both the magnitude and slope declines under imperfect pass-through. The decline is substantial for rural households at the lower end of the distribution, as the share of individuals who are employed in the production of food commodities is larger.

The consumption and wage income effects are combined in equation (18) to generate a distribution of the net welfare effect for each household, with mean $\hat{W}_{h}$ and standard error $\sigma_{W_{h}}$, shown in the bottom panel of Table 10. Welfare effects are negative throughout, except for rural households in the lowest decile under perfect pass-through, suggesting that welfare gains through wage incomes dominate the welfare loss through consumption. For rural households, net welfare decreases as one moves up the distribution, although the decline is not monotonic at higher deciles. For urban households, welfare losses are larger and regressive as well. The lowest decile suffers a $6 \%$ welfare loss, which decreases to $4.3 \%$ at the highest decile.

These effects can be seen in Figure 7. They are progressive with a sharp negative slope among rural households, but regressive for urban households. This is because the positive price shocks confer large welfare benefits through the wage income channel at the lower end of the distribution. For urban households, the welfare gains through wage incomes are small and not enough to offset the welfare loss through consumption. 
TABLE 10. Effect on consumption, wages, and welfare.

\begin{tabular}{|c|c|c|c|c|c|c|c|c|}
\hline \multirow[b]{3}{*}{ Decile } & \multicolumn{4}{|c|}{ Perfect Price Pass-Through } & \multicolumn{4}{|c|}{ Imperfect Price Pass-Through } \\
\hline & \multicolumn{2}{|c|}{ Rural } & \multicolumn{2}{|c|}{ Urban } & \multicolumn{2}{|c|}{ Rural } & \multicolumn{2}{|c|}{ Urban } \\
\hline & Mean & SE & Mean & SE & Mean & SE & Mean & SE \\
\hline & \multicolumn{8}{|c|}{ Consumption } \\
\hline 1 & -6.030 & 0.111 & -6.321 & 0.270 & -3.955 & 0.190 & -3.631 & 0.060 \\
\hline 2 & -5.957 & 0.109 & -6.083 & 0.250 & -3.831 & 0.183 & -3.455 & 0.057 \\
\hline 3 & -5.851 & 0.107 & -5.917 & 0.239 & -3.770 & 0.179 & -3.394 & 0.056 \\
\hline 4 & -5.724 & 0.105 & -5.787 & 0.229 & -3.665 & 0.174 & -3.317 & 0.055 \\
\hline 5 & -5.565 & 0.102 & -5.629 & 0.216 & -3.483 & 0.165 & -3.182 & 0.053 \\
\hline 6 & -5.439 & 0.100 & -5.405 & 0.205 & -3.475 & 0.164 & -3.088 & 0.051 \\
\hline 7 & -5.334 & 0.098 & -5.211 & 0.198 & -3.379 & 0.159 & -3.001 & 0.050 \\
\hline 8 & -5.062 & 0.093 & -5.000 & 0.188 & -3.229 & 0.152 & -2.962 & 0.049 \\
\hline 9 & -4.838 & 0.089 & -4.743 & 0.180 & -3.215 & 0.150 & -2.905 & 0.048 \\
\hline 10 & -4.038 & 0.074 & -4.316 & 0.164 & -2.573 & 0.120 & -2.764 & 0.046 \\
\hline \multirow[t]{2}{*}{ Overall } & -5.384 & 0.099 & -5.441 & 0.214 & -3.458 & 0.163 & -3.170 & 0.052 \\
\hline & \multicolumn{8}{|c|}{ Wage income } \\
\hline 1 & 7.030 & 0.173 & 0.183 & 0.139 & 1.733 & 0.038 & 0.034 & 0.018 \\
\hline 2 & 4.550 & 0.175 & 0.104 & 0.108 & 1.055 & 0.039 & 0.025 & 0.018 \\
\hline 3 & 3.503 & 0.171 & 0.089 & 0.101 & 1.112 & 0.042 & 0.034 & 0.018 \\
\hline 4 & 2.975 & 0.172 & 0.047 & 0.125 & 0.952 & 0.044 & 0.013 & 0.017 \\
\hline 5 & 2.124 & 0.171 & 0.019 & 0.081 & 0.636 & 0.044 & 0.006 & 0.018 \\
\hline 6 & 1.434 & 0.169 & 0.022 & 0.074 & 0.392 & 0.045 & 0.003 & 0.008 \\
\hline 7 & 1.239 & 0.152 & 0.006 & 0.047 & 0.332 & 0.045 & 0.001 & 0.005 \\
\hline 8 & 0.608 & 0.172 & 0.009 & 0.051 & 0.125 & 0.046 & 0.001 & 0.005 \\
\hline 9 & 0.391 & 0.176 & 0.001 & 0.036 & 0.086 & 0.053 & 0.000 & 0.007 \\
\hline 10 & 0.145 & 0.173 & 0.000 & 0.011 & 0.049 & 0.065 & 0.000 & 0.006 \\
\hline \multirow[t]{2}{*}{ Overall } & 2.400 & 0.171 & 0.048 & 0.077 & 0.647 & 0.046 & 0.012 & 0.012 \\
\hline & \multicolumn{8}{|c|}{ Net welfare } \\
\hline 1 & 1.000 & 0.111 & -6.138 & 0.270 & -2.222 & 0.190 & -3.597 & 0.060 \\
\hline 2 & -1.407 & 0.109 & -5.979 & 0.250 & -2.777 & 0.183 & -3.430 & 0.057 \\
\hline 3 & -2.348 & 0.107 & -5.828 & 0.239 & -2.658 & 0.179 & -3.360 & 0.056 \\
\hline 4 & -2.748 & 0.105 & -5.740 & 0.229 & -2.713 & 0.174 & -3.304 & 0.055 \\
\hline 5 & -3.441 & 0.102 & -5.610 & 0.216 & -2.847 & 0.165 & -3.177 & 0.053 \\
\hline 6 & -4.005 & 0.100 & -5.383 & 0.205 & -3.083 & 0.164 & -3.085 & 0.051 \\
\hline 7 & -4.095 & 0.098 & -5.205 & 0.198 & -3.047 & 0.159 & -3.000 & 0.050 \\
\hline 8 & -4.454 & 0.093 & -4.991 & 0.188 & -3.103 & 0.152 & -2.960 & 0.049 \\
\hline 9 & -4.447 & 0.089 & -4.742 & 0.180 & -3.129 & 0.150 & -2.905 & 0.048 \\
\hline 10 & -3.893 & 0.074 & -4.316 & 0.164 & -2.524 & 0.120 & -2.764 & 0.046 \\
\hline Overall & -2.984 & 0.099 & -5.393 & 0.214 & -2.810 & 0.163 & -3.158 & 0.052 \\
\hline
\end{tabular}

Note: SE denotes standard errors, estimated through replications based on sampling from the distribution of commodity price shocks.

\section{Impact on poverty}

The poverty impact is estimated by comparing the number of poor individuals before and after the price change. Let the poverty line be defined by $z$. Then the poverty rate, $P$, is defined as the proportion of population below the poverty line. This headcount ratio 


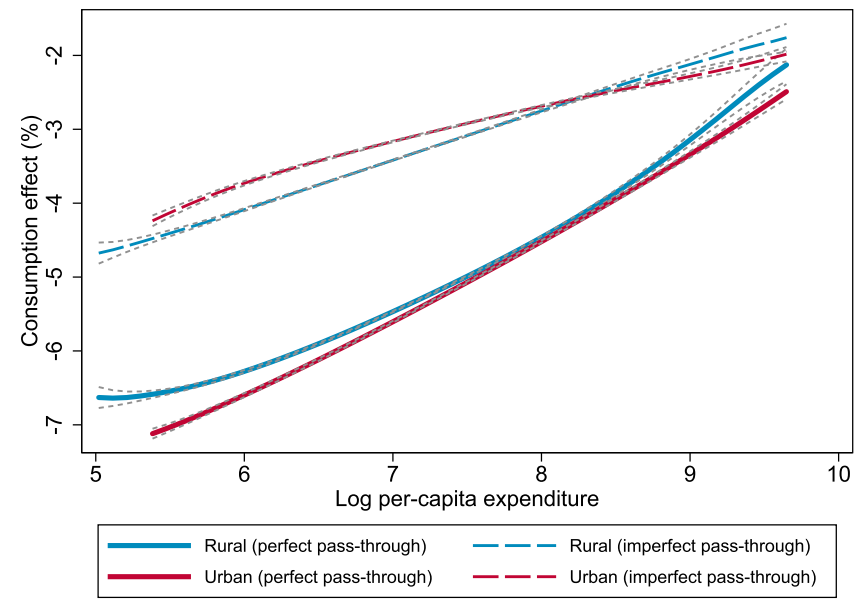

Figure 5. Effect of the mandate on household consumption. Notes: Local polynomial regression of consumption on log per capita household expenditure.

definition for the poverty rate is given by

$$
P=\frac{1}{K} \sum_{i=1}^{K} I\left(x_{i} \leq z\right),
$$

where $K$ is the total number of individuals, $x_{i}$ is per capita expenditure of individual $i$, and $I(\cdot)$ is an indicator function that takes the value of one for individuals that are below the poverty line, that is, for whom $x_{i} \leq z$.

The price shock impacts household expenditures through two channels. First, higher food prices increase wage incomes of individuals who work in industries that

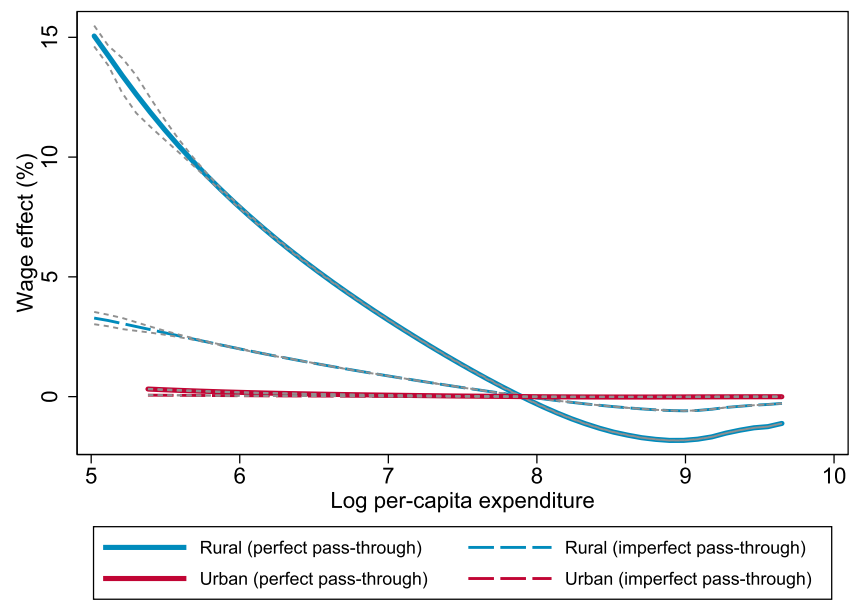

FIGURE 6. Effect of the mandate on household wage income. Notes: Local polynomial regression of wage income effects on log per capita household expenditure. 


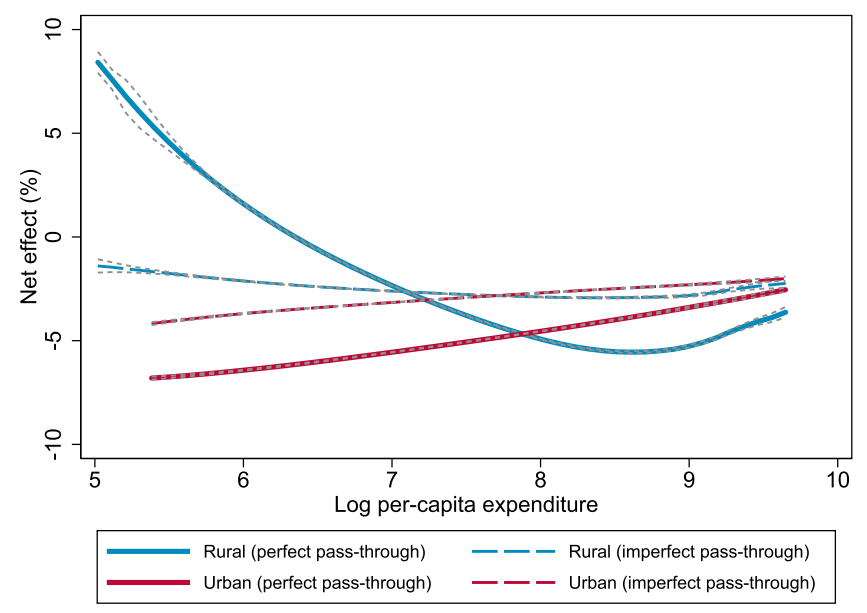

FIgURE 7. Effect of the mandate on welfare. Notes: Local polynomial regression of net welfare on log per capita household expenditure.

are directly affected. This will increase the per capita expenditure of the household in direct proportion to the share of wage income from industry $i$ in the household budget, thereby shifting the household expenditure distribution upwards. The second effect is through a shift in the poverty line $z$ to the right as the same basket of goods is now more costly. These effects are captured by

$$
d z=\sum_{i} \bar{\theta}_{i} d \ln p_{i}
$$

where $\bar{\theta}_{i}$ is the average expenditure share of the "marginal poor," defined as households within a 5\% range of the poverty line (De Janvry and Sadoulet (2010), Porto (2010)). We use the international poverty line $(z)$ of $\$ 1.25$ per day which is equivalent to Rs 701.25 per month. ${ }^{6}$

This poverty line is used to partition poor and non-poor individuals prior to the price shock and to identify households that change their poverty status. Households who were marginally poor prior to the price change may no longer be poor if the share of income from affected industries is relatively high. At the same time, the marginally nonpoor may become poor if their income share is low. Each household is marked as poor and non-poor according to $I\left(x_{i} \leq z\right)$ before and after the policy change. The change in poverty rate is computed as $\Delta P=P_{\text {pre }}-P_{\text {post }}$ where $P_{\text {pre }}$ and $P_{\text {post }}$ are the poverty rates before and after the price increase, respectively. These changes are computed for each vector of the price shock drawn from the distribution estimated earlier, yielding a mean $\Delta \widehat{P}$ and standard error $\sigma_{P}$ for the poverty estimates.

Table 11 shows mean poverty impacts. It is about two percentage points for rural households under perfect pass-through and slightly larger, 2.18 percentage points un-

\footnotetext{
${ }^{68}$ This implies that the "marginal poor" is a household with per capita expenditure between Rs 666.2 and Rs 736.3, using the 2010 purchasing power parity (PPP) of Rs 18.7 (World Bank Development Indicators). A month is assumed to be 30 days.
} 
TABLE 11. Number of new poor created by the mandate.

\begin{tabular}{|c|c|c|c|c|c|}
\hline & \multicolumn{2}{|c|}{ Rural } & \multicolumn{2}{|c|}{ Urban } & \multirow[b]{2}{*}{$\begin{array}{l}\text { Total New Poor } \\
\text { (Million) }\end{array}$} \\
\hline & $\begin{array}{c}\text { Change in } \\
\text { Poverty Rate }\end{array}$ & $\begin{array}{c}\text { New Poor } \\
\text { (Million) }\end{array}$ & $\begin{array}{c}\text { Change in } \\
\text { Poverty Rate }\end{array}$ & $\begin{array}{c}\text { New Poor } \\
\text { (Million) }\end{array}$ & \\
\hline \multicolumn{6}{|c|}{ Perfect Pass-through } \\
\hline Mean & $\begin{array}{c}2.052 \\
(0.000)\end{array}$ & 19.792 & $\begin{array}{c}1.361 \\
(0.005)\end{array}$ & 6.180 & 25.591 \\
\hline \multicolumn{6}{|c|}{ Imperfect Pass-through } \\
\hline Mean & $\begin{array}{c}2.175 \\
(0.005)\end{array}$ & 20.985 & $\begin{array}{c}0.829 \\
(0.001)\end{array}$ & 3.766 & 24.751 \\
\hline
\end{tabular}

Note: Standard errors are in parentheses. The $\$ 1.25$ poverty line is converted to Rupees using 2010 purchasing power parity. The number of new poor is computed using year 2022 UN projected population for India of 1.42 billion (UNDP (2015)).

der imperfect pass-through. In the latter case, marginally poor individuals rely relatively more on wage incomes from food-related industries, which is adversely impacted when the pass-through is muted. The corresponding figures for urban households are 1.36 and 0.83 percentage points-lower because they are less concentrated around the poverty line. The standard errors in all cases show that the mean poverty effects are precisely estimated.

India is home to a significant share of the world's poor. In order to gauge the size of the affected population, we can use United Nations population projections for 2022 (UNDP (2015)). These poverty rates translate to about 20 million new rural poor and between 3.8 and 6.2 million urban poor. Overall, our results imply that the US Renewable Fuel Standard increases the number of poor individuals in India by approximately 25 million people.

The numbers for urban poor are lower partly because of the smaller size of the Indian urban population. Moreover, the concentration of population around the poverty line varies between urban and rural areas. Figure 8 shows kernel densities for the rural and urban populations relative to the international poverty line. The higher rural population density near the poverty line leads to a higher share falling below the line when it shifts to the right. This can also be seen by comparing the share of the "marginal poor." About $5.5 \%$ of rural households, but only $2.9 \%$ for urban households, have per capita incomes within 5\% range of the poverty line. Urban households suffer a larger welfare loss, but a smaller number of them are located near the poverty line. On the other hand, rural households experience lower welfare effects, but a larger poverty impact. These results highlight the need to study the entire distribution of welfare impacts rather than estimating a single statistic such as the poverty rate.

\section{Welfare effects by household characteristics}

We have focused on household heterogeneity in terms of their consumption basket, income and labor market characteristics. These sources of variation are expected to be correlated with other characteristics of the household. Certain groups may be more or 


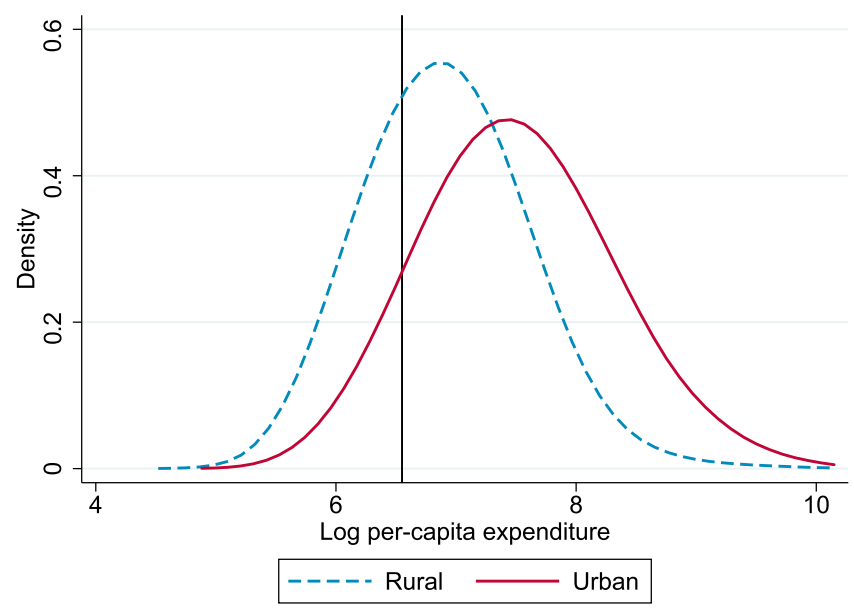

Figure 8. Kernel densities around the poverty line. Notes: Kernel densities for per capita expenditure are shown. The half-width kernel of 0.5 and sampling weights are used in density estimation. The vertical line represents the log international poverty line of $\$ 1.25$ converted to rupees (i.e., $\ln (701.25)=6.55)$.

less impacted due to factor ownership or dietary preferences. Here, we dissect the consumption and wage effects across different groups of households using a series of mean comparison tests. ${ }^{69}$

In Table 12, we first report results across factor ownership of households, particularly land and skilled labor. Both landowners and the landless suffer similar welfare impacts through the consumption channel, as seen in column (1). However, the welfare gains through the wage channel are higher for those who own land, the difference being statistically significant. The effects are similar among urban households. Next, we compare the skill level of the household head. As expected, unskilled households experience a larger loss through the consumption channel, mainly because they tend to be poorer. However, they see larger welfare gains through the wage channel because they work predominantly in the agriculture sector.

Gender comparisons are made in the third panel. ${ }^{70}$ Households with a male head accrue lower losses through the consumption channel and larger welfare gains through the wage income channel. Hence, overall welfare losses are significantly lower for those with male heads. Religious identity of households may be important to the extent that they are correlated with dietary habits. For example, many Hindus are vegetarians, and tend to consume less animal protein relative to Muslims. Rural Hindu households exhibit larger consumption effects, but gain more through the wage income channel, leading to a smaller net welfare loss compared to other households.

\footnotetext{
${ }^{69}$ We only report the estimates for perfect pass-though.

${ }^{70}$ Approximately $12 \%$ of rural households and $14 \%$ of urban households have female heads.
} 
TAвLE 12. Welfare effects by household characteristics.

\begin{tabular}{|c|c|c|c|c|c|c|}
\hline & \multicolumn{3}{|c|}{ Rural } & \multicolumn{3}{|c|}{ Urban } \\
\hline & $\begin{array}{c}\text { Consumption } \\
\text { (1) }\end{array}$ & $\begin{array}{l}\text { Wages } \\
(2)\end{array}$ & $\begin{array}{c}\text { Welfare } \\
\text { (3) }\end{array}$ & $\begin{array}{c}\text { Consumption } \\
\text { (4) }\end{array}$ & $\begin{array}{l}\text { Wages } \\
(5)\end{array}$ & $\begin{array}{c}\text { Welfare } \\
\text { (6) }\end{array}$ \\
\hline \multicolumn{7}{|l|}{ Land ownership } \\
\hline Landowner & $\begin{array}{c}-5.428 \\
(0.004)\end{array}$ & $\begin{array}{c}2.833 \\
(0.010)\end{array}$ & $\begin{array}{c}-2.606 \\
(0.010)\end{array}$ & $\begin{array}{r}-5.202 \\
(0.007)\end{array}$ & $\begin{array}{c}0.037 \\
(0.001)\end{array}$ & $\begin{array}{c}-5.180 \\
(0.007)\end{array}$ \\
\hline Landless & $\begin{array}{c}-5.310 \\
(0.025)\end{array}$ & $\begin{array}{c}2.287 \\
(0.051)\end{array}$ & $\begin{array}{c}-3.055 \\
(0.049)\end{array}$ & $\begin{array}{c}-4.991 \\
(0.014)\end{array}$ & $\begin{array}{c}0.025 \\
(0.001)\end{array}$ & $\begin{array}{c}-4.986 \\
(0.014)\end{array}$ \\
\hline$\Delta$ & $\begin{array}{c}-0.118 \\
(0.021)\end{array}$ & $\begin{array}{c}0.546 \\
(0.050)\end{array}$ & $\begin{array}{c}0.450 \\
(0.047)\end{array}$ & $\begin{array}{r}-0.211 \\
(0.015)\end{array}$ & $\begin{array}{c}0.013 \\
(0.001)\end{array}$ & $\begin{array}{c}-0.193 \\
(0.014)\end{array}$ \\
\hline t-stat & -5.554 & 10.996 & 9.498 & -14.365 & 13.301 & -13.477 \\
\hline \multicolumn{7}{|l|}{ Skill } \\
\hline Unskilled & $\begin{array}{c}-5.705 \\
(0.007)\end{array}$ & $\begin{array}{c}3.636 \\
(0.021)\end{array}$ & $\begin{array}{c}-2.071 \\
(0.020)\end{array}$ & $\begin{array}{c}-5.848 \\
(0.014)\end{array}$ & $\begin{array}{c}0.072 \\
(0.001)\end{array}$ & $\begin{array}{c}-5.779 \\
(0.014)\end{array}$ \\
\hline Skilled & $\begin{array}{r}-5.296 \\
(0.005)\end{array}$ & $\begin{array}{c}2.437 \\
(0.011)\end{array}$ & $\begin{array}{r}-2.875 \\
(0.011)\end{array}$ & $\begin{array}{c}-5.007 \\
(0.007)\end{array}$ & $\begin{array}{c}0.026 \\
(0.000)\end{array}$ & $\begin{array}{c}-4.999 \\
(0.007)\end{array}$ \\
\hline$\Delta$ & $\begin{array}{c}-0.408 \\
(0.009)\end{array}$ & $\begin{array}{c}1.199 \\
(0.022)\end{array}$ & $\begin{array}{c}0.804 \\
(0.021)\end{array}$ & $\begin{array}{c}-0.841 \\
(0.017)\end{array}$ & $\begin{array}{c}0.045 \\
(0.001)\end{array}$ & $\begin{array}{r}-0.780 \\
(0.016)\end{array}$ \\
\hline t-stat & -43.433 & 55.667 & 38.690 & -50.388 & 41.972 & -47.855 \\
\hline \multicolumn{7}{|l|}{ Gender } \\
\hline Male & $\begin{array}{c}-5.416 \\
(0.005)\end{array}$ & $\begin{array}{c}2.826 \\
(0.011)\end{array}$ & $\begin{array}{c}-2.602 \\
(0.010)\end{array}$ & $\begin{array}{c}-5.133 \\
(0.007)\end{array}$ & $\begin{array}{c}0.033 \\
(0.000)\end{array}$ & $\begin{array}{c}-5.115 \\
(0.007)\end{array}$ \\
\hline Female & $\begin{array}{c}-5.476 \\
(0.015)\end{array}$ & $\begin{array}{c}2.668 \\
(0.031)\end{array}$ & $\begin{array}{c}-2.828 \\
(0.030)\end{array}$ & $\begin{array}{c}-5.257 \\
(0.019)\end{array}$ & $\begin{array}{c}0.039 \\
(0.001)\end{array}$ & $\begin{array}{c}-5.245 \\
(0.019)\end{array}$ \\
\hline$\Delta$ & $\begin{array}{c}0.060 \\
(0.014)\end{array}$ & $\begin{array}{c}0.158 \\
(0.033)\end{array}$ & $\begin{array}{c}0.226 \\
(0.032)\end{array}$ & $\begin{array}{c}0.125 \\
(0.020)\end{array}$ & $\begin{array}{c}-0.005 \\
(0.001)\end{array}$ & $\begin{array}{c}0.130 \\
(0.019)\end{array}$ \\
\hline t-stat & 4.210 & 4.769 & 7.167 & 6.387 & -4.120 & 6.814 \\
\hline \multicolumn{7}{|l|}{ Religion } \\
\hline Hindu & $\begin{array}{c}-5.460 \\
(0.005)\end{array}$ & $\begin{array}{c}2.914 \\
(0.012)\end{array}$ & $\begin{array}{c}-2.555 \\
(0.011)\end{array}$ & $\begin{array}{c}-5.095 \\
(0.007)\end{array}$ & $\begin{array}{c}0.034 \\
(0.000)\end{array}$ & $\begin{array}{c}-5.079 \\
(0.007)\end{array}$ \\
\hline Islam and other & $\begin{array}{r}-5.296 \\
(0.010)\end{array}$ & $\begin{array}{c}2.450 \\
(0.020)\end{array}$ & $\begin{array}{r}-2.866 \\
(0.019)\end{array}$ & $\begin{array}{c}-5.309 \\
(0.013)\end{array}$ & $\begin{array}{c}0.035 \\
(0.001)\end{array}$ & $\begin{array}{c}-5.286 \\
(0.012)\end{array}$ \\
\hline$\Delta$ & $\begin{array}{c}-0.164 \\
(0.010)\end{array}$ & $\begin{array}{c}0.464 \\
(0.024)\end{array}$ & $\begin{array}{c}0.311 \\
(0.023)\end{array}$ & $\begin{array}{c}0.214 \\
(0.015)\end{array}$ & $\begin{array}{c}-0.001 \\
(0.001)\end{array}$ & $\begin{array}{c}0.208 \\
(0.014)\end{array}$ \\
\hline t-stat & -15.671 & 19.087 & 13.405 & 14.450 & -1.315 & 14.369 \\
\hline
\end{tabular}

Note: Household classification is based on characteristics reported in the 66th round of the NSS Household Expenditure Survey. Gender refers to the gender of the household head. A household is unskilled if the household head is illiterate. $t$-statistics of the mean comparison tests are reported. $\Delta$ denotes the difference in the mean impact.

\section{Concluding Remarks}

In this paper, we study the effect of the US Renewable Fuel Mandate on household consumption and income in a developing country. We show significant welfare impacts consumption effects tend to be regressive because the poor spend a larger portion of 
their expenditure on food. Wage impacts are progressive because the poor are likely to be employed in the agriculture sector and, therefore, benefit from higher wages. The net effect is progressive for rural populations and regressive for those living in towns and cities, because the latter bear large consumption losses but gain little through the wage channel. However, because a larger number of poor people live in villages, poverty impacts are disproportionately higher for rural households. We estimate that about 2526 million are likely to become poor as a result of the RFS. These figures are robust to assumptions about the pass-through of world prices to the domestic Indian market.

These impacts may multiply several fold if other countries with rapidly-growing transportation sectors also turn to biofuels as a way of reducing their energy dependence. Some countries such as those of the European Union already have a significant mandate in place, although not as large as the one in the US. India and China have mandates in the books. In the long-run of course, these price effects may be mitigated by bringing new land under production and technological improvements in farming. However, to the extent that we must use scarce land, water, and other resources to produce more food and energy, the supply cost of food commodities is likely to increase, and food price shocks may linger for an extended time period. Other factors such as climatic shifts and droughts may also affect commodity prices and exacerbate these distributional impacts. Even with the Renewable Fuel Standard, the poverty impacts we report may be much larger if other poor countries such as those in sub-Saharan Africa are included in the analysis.

An important data limitation is that the welfare estimations focus only on consumption and wage incomes, excluding important channels such as agricultural profits. However, including farm profits is unlikely to make a big difference in our estimates because the poor do not own significant economic assets. We do not take into account general equilibrium impacts driven by factor reallocation across sectors. This requires price data from other sectors, including services such as education and health, data for which is not readily available for a developing country like India. However, the magnitude of the general equilibrium impacts is likely to be small as service sectors are highly regulated in India and they may not be very sensitive to commodity price shocks.

This research can be extended in other directions. The micro-level impacts in India can be compared with that in other countries with significant poor populations to check if the composition of the welfare effects is fundamentally different and idiosyncratic to diet and other cultural factors. For example, societies in which the diet is based on corn or a higher consumption of meat and dairy may be impacted differently. Countries adopt different policies to mitigate the effect of price shocks, which can again be compared to obtain policy insights. Ultimately, these price shocks will affect nutritional intake among individuals and affect the allocation of calories within each household. Each consumption item in the NSS data we have used can be matched to its calorie, fat, and protein content using the FAO nutritional database. The price shocks are likely to alter the consumption structure of households. It may then be possible to estimate the number of individuals that will move below the recommended minimum daily nutritional intake, and isolate the effects on particular segments of the population, such as women and children. 


\section{REFERENCES}

Anderson, S. (2011), "Caste as an impediment to trade." American Economic Journal: Applied Economics, 3 (1), 239-263. [1173, 1179, 1180]

Bento, A. M., L. H. Goulder, M. R. Jacobsen, and R. H. Von Haefen (2009), "Distributional and efficiency impacts of increased US gasoline taxes." The American Economic Review, 99 (3), 667-699. [1155]

Besley, T. and R. Burgess (2004), "Can labor regulation hinder economic performance? Evidence from India.” The Quarterly Journal of Economics, 119 (1), 91-134. [1173]

Bourguignon, F., M. Bussolo, and L. A. Pereira da Silva (2008), "Introduction: Evaluating the Impact of Macroeconomic Policies on Poverty and Income Distribution." In The Impact of Macroeconomic Policies on Poverty and Income Distribution (F. Bourguignon, M. Bussolo, and L. A. Pereira da Silva, eds.), 1-23, Palgrave MacMillan and the World Bank. [1155]

Bouwman, A. (1997), Long-Term Scenarios of Livestock-Crop-Land Use Interactions in Developing Countries. Food and Agriculture Organisation, Rome. [1162]

Boyce, J. and M. Ravallion (1991), "A dynamic econometric model of agricultural wage determination in Bangladesh." Oxford Bulletin of Economics and Statistics, 53 (4), 361376. [1180]

Campa, J. and L. Goldberg (2005), "Exchange Rate Pass-through into Import Prices.” Review of Economics and Statistics, 87 (4), 679-690. [1176]

Campa, J. M. and J. M. Gonzalez Minguez (2006), "Differences in exchange rate passthrough in the euro area." European Economic Review, 50 (1), 121-145. [1176]

CBO (2014), "The renewable fuel standard: Issues for 2014 and beyond. Congressional budget office." Congress of the United States. [1156]

Chakravorty, U., M.-H. Hubert, and B. Marchand (2019), "Supplement to 'Food for fuel: The effect of the US biofuel mandate on poverty in India." Quantitative Economics Supplemental Material, 10, https://doi.org/10.3982/QE942. [1161]

Chakravorty, U., M.-H. Hubert, M. Moreaux, and L. Nøstbakken (2017), "Long-run impact of biofuels on food prices.” The Scandinavian Journal of Economics, 119 (3), 733767. [1163]

Chakravorty, U., B. Magne, and M. Moreaux (2012), "Resource use under climate stabilization: Can nuclear power provide clean energy?" Journal of Public Economic Theory, 14 (2), 349-389. [1163]

Chen, X., H. Huang, and M. Khanna (2012), "Land-use and greenhouse gas implications of biofuels: Role of technology and policy.” Climate Change Economics, 3 (3), 1181-1203. [1163]

Chen, X., H. Huang, M. Khanna, and H. Önal (2014), "Alternative transportation fuel standards: Welfare effects and climate benefits." Journal of Environmental Economics and Management, 67 (3), 241-257. [1162] 
Datt, G. and J. C. Olmsted (2004), "Induced wage effects of changes in food prices in Egypt.” The Journal of Development Studies, 40 (4), 137-166. [1180]

De Janvry, A. and E. Sadoulet (2010), “The global food crisis in Guatemala: What crisis and for whom?" World Development, 38 (9), 1328-1339. [1168, 1176, 1184]

Deaton, A. (2000), The Analysis of Household Surveys: A Microeconomic Approach to Development Policy. Johns Hopkins University Press. [1178]

Deaton, A. (1989), "Rice Prices and Income Distribution in Thailand: A Non-Parametric Analysis.” Economic Journal, 99 (395), 1-37. [1168]

Dimaranan, B., R. McDougall, and T. Hertel (2007), "Behavioral parameters. GTAP data base documentation.” Available at https://www.gtap.agecon.purdue.edu/resources/ download/861.pdf. [1163, 1166, 1171]

Dreze, J. P. and A. Mukherjee (1989), Labor Contracts in Rural India: Theories and Evidence. Macmillan Press. [1180]

EIA (2014), “International Energy Statistics, 2013.” U.S. Energy Information Administration, Washington DC, USA. [1162]

EIA (2015), “International Energy Outlook, 2014.” U.S. Energy Information Administration, Washington DC, USA. [1164]

EPA (2010), “Renewable Fuel Standard Program (RFS2) Regulatory Impact Analysis.” US Environmental Protection Agency, Washington, DC. [1154, 1156, 1164]

FAO (2010), "The State of Food Insecurity in the World: Addressing the Protracted Crisis." Food and Agricultural Organization, Rome. [1154]

FAO (2016), “Statistical databases.” Food and Agriculture Organization of the United Nations. [1159, 1160, 1161, 1166]

FAO-IIASA (2002), “Global Agro-Ecological Zone.” Food Agriculture Organization and International Institute for Applied Systems Analysis. [1161]

Fischer, G., M. Shah, H. van Velthuizen, and F. Nachtergaele (2001), "Global agroecological assessment for agriculture in the 21 st century." International Institute for Applied Systems Analysis. [1159]

Gelfand, I., R. Sahajpal, X. Zhang, R. C. Izaurralde, K. L. Gross, and G. P. Robertson (2013), "Sustainable bioenergy production from marginal lands in the us midwest." Nature, 493 (7433), 514-517. [1162]

Golub, A., T. W. Hertel, and B. Sohngen (2009), "Land use modelling in a recursively dynamic GTAP framework." In Economic Analysis of Land Use in Global Climate Change Policy, 235. [1160]

Gopinath, G. and A. Burstein (2014), "International prices and exchange rates.” Handbook of International Economics. [1174] 
Gouel, C. and T. Hertel (2006), "Introducing Forest Access Cost Functions into a General Equilibrium Model.” GTAP Working Research Memorandum, no. 8. Available at https: //www.gtap.agecon.purdue.edu/resources/download/2899.pdf. [1161]

GTAP 5 (1997), “Global trade analysis project database documentation.” Purdue University. [1161]

Han, J., R. Liu, B. U. Marchand, and J. Zhang (2016), "Market structure, imperfect tariff pass-through, and household welfare in urban China." Journal of International Economics, 100, 220-232. [1168]

Hausman, C., M. Auffhammer, and P. Berck (2012), "Farm Acreage Shocks and Crop Prices: An SVAR Approach to Understanding the Impacts of Biofuels." Environmental and Resource Economics, 53 (1), 1-20. [1154, 1165]

Hertel, T., W. Tyner, and D. Birur (2010), “The global impacts of biofuel mandates.” Energy Journal, 31 (1), 75-100. [1162]

IEA (2014), “Key world energy statistics.” International Energy Agency. [1163]

Jacoby, H. G. (2016), “Food prices, wages, and welfare in rural India." Economic Inquiry, 54 (1), 159-176. [1178, 1179]

Kwiecinski, A. and D. Jones (2010), "Policy Responses in Emerging Economies to International Agricultural Commodity Price Surges.” Organisation for Economic Co-operation and Development (OECD). [1174]

Mazzolari, F. and G. Ragusa (2013), "Spillovers from high-skill consumption to low-skill labor markets.” Review of Economics and Statistics, 95 (1), 74-86. [1179]

Mitchell, D. (2008), “A note on rising food prices.” World Bank, Policy Research Working Paper Series 4682. [1154]

Mittal, S. (2006), "Structural shift in demand for food: Projections for 2020." Indian Council for Research on International Economic Relations (ICRIER). [1166]

MOSPI (2012), Report of the Committee on Unorganised Sector Statistics. Ministry of Statistics and Programme Implementation. [1178]

Muhammad, A., J. L. Seale, B. Meade, and A. Regmi (2011), "International evidence on food consumption patterns: An update using 2005 international comparison program data.” Technical Bulletin 125. [1163]

Mundlak, Y. and D. Larson (1992), “On the transmission of world agricultural prices.” The World Bank Economic Review, 6 (3), 399-422. [1176]

Munshi, K. and M. Rosenzweig (2009), "Why is mobility in India so low? Social insurance, inequality, and growth.” NBER Working Papers 14850, National Bureau of Economic Research, Inc. [1173, 1179]

Nicita, A. (2009), "The price effect of tariff liberalization: Measuring the impact on household welfare." Journal of Development Economics, 89 (1), 19-27. [1168] 
Nordhaus, W. D. (2009), “The Economics of an Integrated World Oil Market.” In International Energy Workshop, 17-19. [1162]

Parry, I. W. and K. A. Small (2005), "Does Britain or the United States have the right gasoline tax?" The American Economic Review, 95 (4), 1276-1289. [1163, 1166]

Paul, S. (2011), "Food Preference and Nutrition in India." Available at SSRN https://ssrn. com/abstract=1960295 or http://dx.doi.org/10.2139/ssrn.1960295. [1163, 1166]

Porto, G. (2006), "Using survey data to assess the distributional effects of trade policy." Journal of International Economics, 70 (1), 140-160. [1178]

Porto, G. (2010), “International market access and poverty in Argentina.” Review of International Economics, 18 (2), 396-407. [1168, 1178, 1179, 1184]

Ravallion, M. (1990), "Rural welfare effects of food price changes under induced wage responses: Theory and evidence for Bangladesh." Oxford Economic Papers, 42 (3), 574585. [1168, 1178]

Ravindranath, N., C. Sita Lakshmi, R. Manuvie, and P. Balachandra (2011), "Biofuel production and implications for land use, food production and environment in India." Energy Policy, 39 (10), 5737-5745. [1160, 1162]

Regmi, A., M. Deepak, J. Jr. Seale, and J. Bernstein (2001), “Cross-country analysis of food consumption patterns." In Changing Structure of Global Food Consumption and Trade, 14-22. [1163, 1166, 1171]

Regmi, A. and J. L. Seale (2011), "Cross-price elasticities of demand across 114 countries.” Technical Bulletin, number 1929. [1163, 1164]

Roberts, M. J. and W. Schlenker (2013), "Identifying Supply and Demand Elasticities of Agricultural Commodities: Implications for the US Ethanol Mandate." American Economic Review, 103 (6), 2268-2295. [1163, 1165, 1166]

Rosegrant, M., T. Zhu, S. Msangi, and T. Sulser (2008), "Global scenarios for biofuels: Impacts and implications." Applied Economic Perspectives and Policy, 30 (3), 495-505. [1154]

Rosenthal, E. (2011), "Rush to use crops as fuel raises food prices and hunger fears." The New York Times. [1154]

Scott, P. T. (2013), "Dynamic discrete choice estimation of agricultural land use." Toulouse School of Economics Working Paper 526. [1165]

Sohngen, B. and R. Mendelsohn (2003), "An optimal control model of forest carbon sequestration." American Journal of Agricultural Economics, 85 (2), 448-457. [1161]

Supreet, K. (2014), "Nominal wage rigidity in village labor markets." National Bureau of Economic Research, 20770. [1180]

UNDP (2010), "Human Development Report 2010: The Real Wealth of Nations: Pathways to Human Development." United Nations Development Programme, New York, NY, USA. [1154] 
Quantitative Economics 10 (2019) Effect of US biofuel mandate on poverty in India 1193

UNDP (2015), “Population Prospects: The 2015 Revision.” The Population Division of the Department of Economic and Social Affairs of the UN Secretariat. [1164, 1185]

Ural Marchand, B. (2012), “Tariff Pass-Through and the Effect of Trade Liberalization on Household Welfare." Journal of Development Economics, 99 (2), 265-281. [1168]

World Bank (2016), “World Databank. World Development Indicators.” [1166]

Co-editor Christopher Taber handled this manuscript.

Manuscript received 9 August, 2017; final version accepted 12 October, 2018; available online 29 November, 2018. 